\title{
Sampling and Analysis Plan for Volatile Organic Compounds in Storm Drains for the Upper East Fork Poplar Creek Characterization Area Remedial Investigation at the Oak Ridge Y-12 Plant, Oak Ridge, Tennessee
}

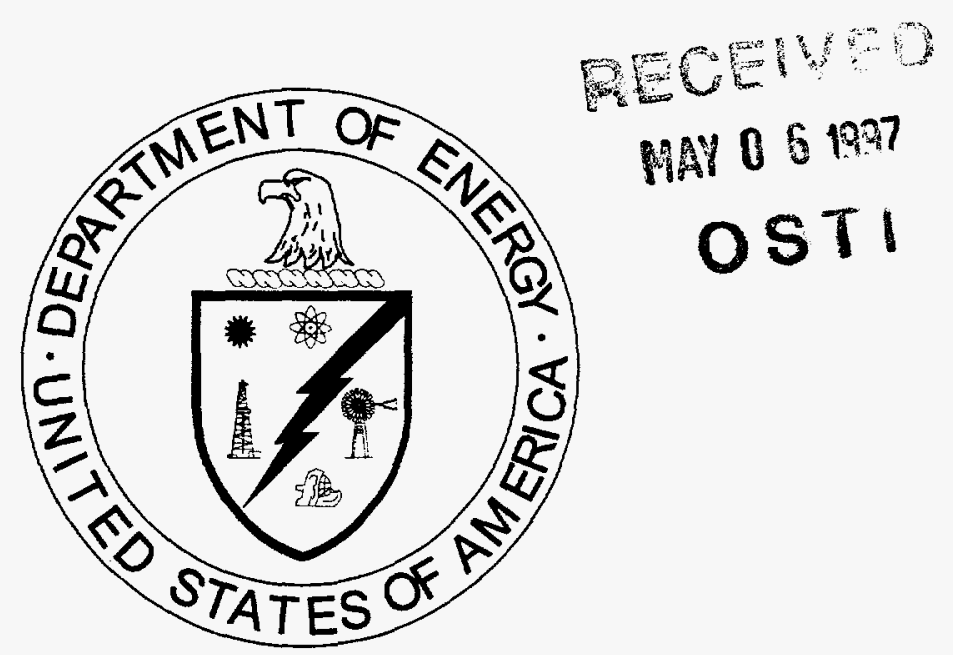


$+$

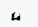

\section{CDM Federal Programs Corporation}

contributed to the preparation of this document and should not be considered an eligible contractor for its review. 


\section{DISCLAIMER}

This report was prepared as an account of work sponsored by an agency of the United States Government. Neither the United States Government nor any agency thereof, nor any of their employees, make any warranty, express or implied, or assumes any legal liability or responsibility for the accuracy, completeness, or usefulness of any information, apparatus, product, or process disclosed, or represents that its use would not infringe privately owned rights. Reference herein to any specific commercial product, process, or service by trade name, trademark, manufacturer, or otherwise does not necessarily constitute or imply its endorsement, recommendation, or favoring by the United States Government or any agency thereof. The views and opinions of authors expressed herein do not necessarily state or reflect those of the United States Government or any agency thereof. 


\section{DISCLAIMER}

Portions of this document may be illegible in electronic image products. Images are produced from the best available original document. 
Energy Systems Environmental Restoration Program

Sampling and Analysis Plan for Volatile Organic Compounds in Storm Drains for the Upper East Fork Poplar Creek Characterization Area Remedial Investigation at the Oak Ridge Y-12 Plant, Oak Ridge, Tennessee

Date Issued-March 1997

\author{
Prepared by \\ CDM Federal Programs Corporation \\ Oak Ridge, Tennessee 37830 \\ under contract 96B-99052C \\ Document Control No. 7907-010-FR-BCRQ \\ Prepared for the \\ U.S. Department of Energy \\ Office of Environmental Management \\ under budget and reporting code EW 20 \\ Environmental Management Activities at the \\ OAK RIDGE Y-12 PLANT \\ Oak Ridge, Tennessee 37831 \\ managed by \\ LOCKHEED MARTIN ENERGY SYSTEMS, INC. \\ for the \\ U.S. DEPARTMENT OF ENERGY \\ under contract DE-AC05-84OR21400
}





\section{PREFACE}

This document was prepared in accordance with requirements under the Comprehensive Environmental Response, Compensation, and Liability Act of 1980 for the Y-12 Environmental Restoration Program. The Upper East Fork Poplar Creek (UEFPC) Characterization Area (CA) is the subject of a remedial investigation (RI). The overall objectives of the UEFPC RI are to evaluate the nature and extent of known and suspected contaminants, to provide the data necessary to perform an ecological risk assessment and a human health risk assessment, to support the evaluation of remedial alternatives for the feasibility study, and to develop a Proposed Plan and Record of Decision for the CA. This document is not a Federal Facility Agreement milestone. This work will be performed under Work Breakdown Structure 1.4.12.1.1.03.41.10.10.12 for Y-12 (Activity Data Sheet 2303, "Upper East Fork Poplar Creek"). 



\section{CONTENTS}

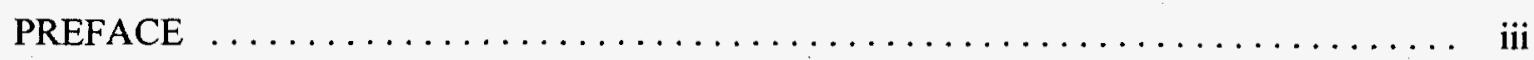

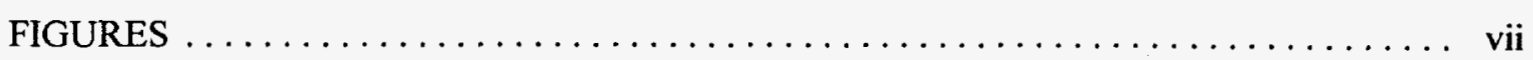

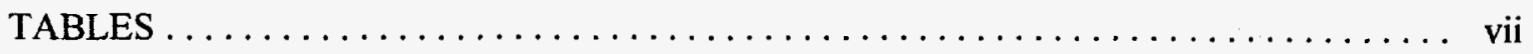

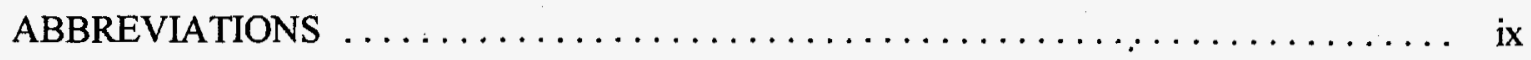

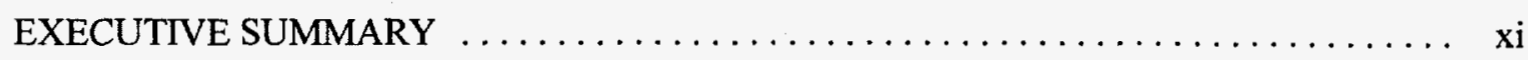

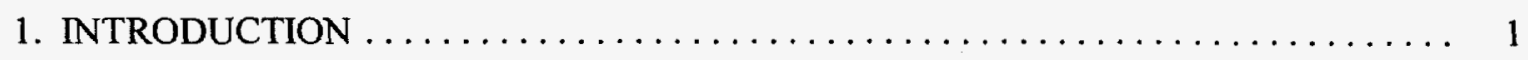

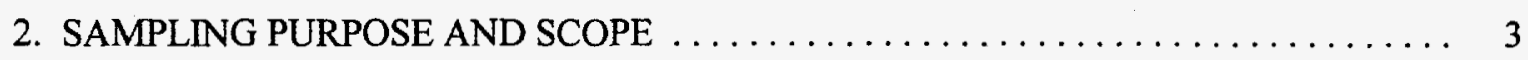

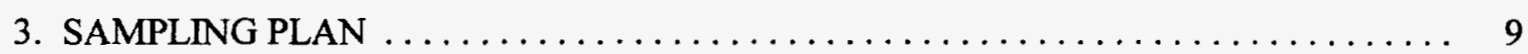

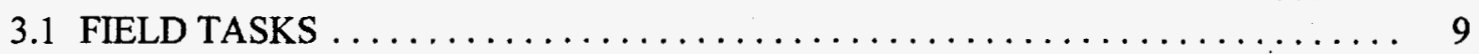

3.2 BEST MANAGEMENT PRACTICES $\ldots \ldots \ldots \ldots \ldots \ldots \ldots \ldots \ldots \ldots \ldots$

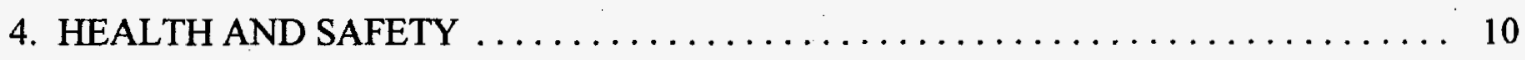

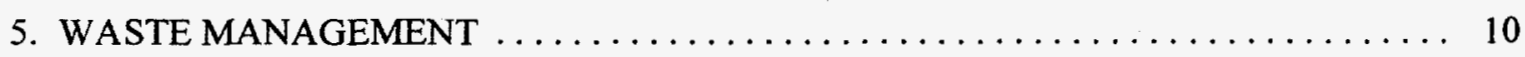

6. QUALITY ASSURANCE/QUALITY CONTROL $\ldots \ldots \ldots \ldots \ldots \ldots \ldots \ldots \ldots \ldots$

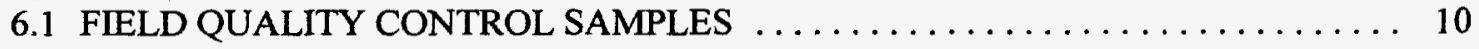

6.2 LABORATORY QUALITY CONTROL REQUIREMENTS $\ldots \ldots \ldots \ldots \ldots \ldots, 11$

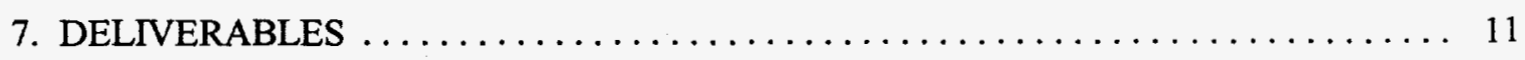

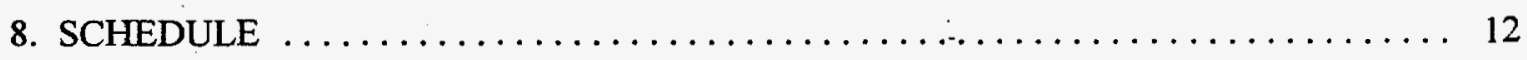

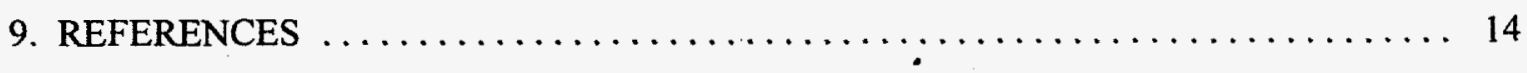

APPENDIX A: PENDING EPA ITMS METHOD $8265 \ldots \ldots \ldots \ldots \ldots \ldots \ldots \ldots$ A-1

APPENDIX B: LABORATORY DATA DELIVERABLES $\ldots \ldots \ldots \ldots \ldots \ldots \ldots$ B-1 


\section{FIGURES}

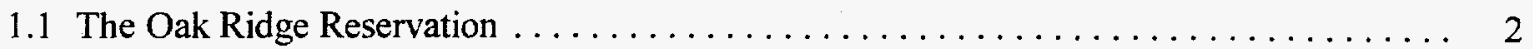

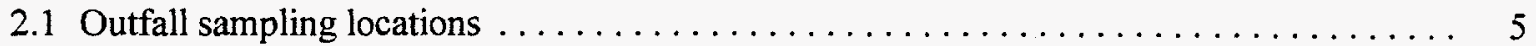

8.1 UEFPC VOCs in storm drains sampling schedule $\ldots \ldots \ldots \ldots \ldots \ldots \ldots \ldots \ldots \ldots$

\section{TABLES}

2.1 Compounds analyzed for in storm drain samples $\ldots \ldots \ldots \ldots \ldots \ldots \ldots \ldots \ldots \ldots$

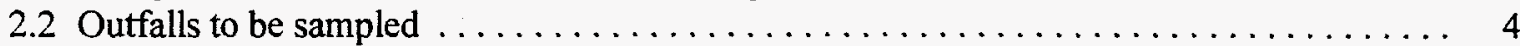

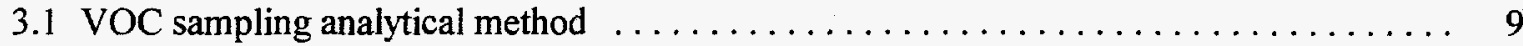

6.1 Summary of field QC samples for sampling of VOCs in storm drains $\ldots \ldots \ldots \ldots \ldots \ldots 11$ 



\begin{tabular}{ll} 
& \multicolumn{1}{c}{ ABBREVIATIONS } \\
CA & \\
CERCLA & $\begin{array}{l}\text { Characterization Area } \\
\text { Comprehensive Environmental Response, Compensation, and Liability Act } \\
\text { of } 1980\end{array}$ \\
CFR & Code of Federal Regulations \\
CLP & Contract Laboratory Program \\
COC & contaminant of concern \\
DOE & U.S. Department of Energy \\
Energy System & Lockheed Martin Energy Systems, Inc. \\
EPA & U.S. Environmental Protection Agency \\
FS & feasibility study \\
HSEA & Health, Safety, Environment, and Accountability \\
ID & identification \\
ITMS & ion trap mass spectrometer \\
ORR & Oak Ridge Reservation \\
QC & quality control \\
RCRA & Resource Conservation and Recovery Act of 1976 \\
RI & remedial investigation \\
SAP & Sampling and Analysis Plan \\
UEFPC & Upper East Fork Poplar Creek \\
VOC & volatile organic compound \\
&
\end{tabular}




\section{EXECUTIVE SUMMARY}

The Oak Ridge Y-12 Plant, located within the Oak Ridge Reservation (ORR), is owned by the U.S. Department of Energy and managed by Lockheed Martin Energy Systems, linc. The Y 12 Plant is one of three major facilities on the ORR. The ORR contains both hazardous-and mixed-waste sites that are subject to regulations promulgated under the Resource Conservation and Recovery Act of 1976 (RCRA) and the Comprehensive Environmental Response, Compensation, and Itability Act of 1980 (CERCLA) as amended by the Superfund Amendments and Reauthorization A ct of 1986. Under RCRA guidelines and requirements from the Tennessee Department of Environment and Conservation, the Y-12 Plant initiated investigation and monitoring of various sites within its boundaries in the mid-1980s. The entire ORR was placed on the National Priorities List of CERCLA sites in November 1989. Following CERCLA guidelines, sites under investigation require a remedial investigation (RI) to define the nature and extent of contamination, evaluate the risks to public health and the environment, and determine the goals for a feasibility study (FS) of potential remedial actions.

The overall objectives of the Upper East Fork Poplar Creek (UEFPC) Characterization Area (CA) RI are to evaluate the nature and extent of known and suspected contaminants, to provide the data necessary to perform an ecological risk assessment and a human health risk assessment, to support the evaluation of remedial alternatives for the FS, to determine the need for early actions, and to develop a Proposed Plan and Record of Decision for the CA. The UEFPC CA, which includes the main Y-12 Plant area, is an operationally and hydrogeologically complex area that contains numerous contaminants and contaminant sources as well as ongoing industrial and defense-related activities.

A substantial amount of historical data exists for the UEFPC CA. Investigations and remedial actions under RCRA and CERCL $A$ have been ongoing since 1983. The streamlined approach that is being used for the UEFPC CA RI will incorporate as much of the historical data as possible. As data needs are identified, additional data will be collected as necessary to support RI characterization, risk assessment, evaluation of FS alternatives, and early action requirements. One data need that has been identified is the lack of information concerning whether contaminated groundwater from the volatile organic compound (VOC) plumes is seeping into the storm drain system. This will also give additional information on the extent of the VOC plumes. Therefore, water samples will be collected from the storm drains and analyzed for VOCs in support of the RI to provide information neeessary to characterize contaminant transport and for the risk assessment. VOC data will be collected from 41 outfalls. 


\section{INTRODUCTION}

Under the Resource Conservation and Recovery Act of 1976 (RCRA) guidelines and requirements from the Tennessee Department of Environment and Conservation, the Oak Ridge Y-12 Plant, one of three major facilities within the U.S. Department of Energy's (DOE's) Oak Ridge Reservation (ORR) (Fig. 1.1), initiated investigation and monitoring of various sites within its boundaries in the mid-1980s. The entire ORR was placed on the National Priorities List of Comprehensive Environmental Response, Compensation, and Liability Act of 1980 (CERCLA) sites in November 1989. Following CERCLA guidelines, sites under investigation require a remedial investigation (RI) to define the nature and extent of contamination, evaluate the risks to public health and the environment, and determine the goals for a feasibility study (FS) of potential remedial actions.

The need to complete RIs in a timely and cost-effective manner resulted in the establishment of the Upper East Fork Poplar Creek (UEFPC) Characterization Area (CA) and the Bear Creek Valley CA for the Y-12 Plant [managed by Lockheed Martin Energy Systems, Inc. (Energy Systems)]. The UEFPC CA consists of the main plant area, and the Bear Creek CA consists of the area west of the Y-12 Plant in Bear Creek Valley. The CA approach considers the entire watershed and examines all the appropriate media within it. The UEFPC CA is an operationally and hydrogeologically complex area that contains numerous contaminants and contaminant sources as well as ongoing industrial and defense-related activities. Boundaries of the UEFPC CA include the base of Pine Ridge to the north, the base of Chestnut Ridge to the south, the eastern boundary of the Bear Creek CA to the west, and the DOE/ORR property line to the east. The actual area of investigation extends beyond the DOE/ORR property line (Scarboro Road) because the groundwater plume boundary extends beyond Scarboro Road. The UEFPC CA is also a suspected source of off-site surface water contamination.

The overall objectives of the UEFPC CA RI are to evaluate the nature and extent of known and suspected contaminants, to provide the data necessary to perform an ecological risk assessment and a human health risk assessment, to support the evaluation of remedial alternatives for the FS, to support early actions, and to develop a Proposed Plan and Record of Decision for the CA.

A substantial amount of historical data exists for the UEFPC CA. Investigations and remedial actions under RCRA and CERCLA have been ongoing since 1983. The streamlined approach that is being used for the UEFPC CA RI will incorporate as much of the historical data as possible. As data needs are identified, additional data will be collected as necessary to support risk assessment and FS needs. One data need that has been identified is the lack of information concerning whether contaminated groundwater from the volatile organic compound (VOC) plumes is seeping into the storm drain system. This information would also help to identify VOC plume extent and discharge points to the surface. Therefore, water samples will be collected from the storm drains and analyzed for VOCs in support of the RI to provide information necessary to characterize contaminant transport and for the risk assessment. This Sampling and Analysis Plan (SAP) addresses VOC sample collection activities in the storm drains. Samples will be collected from 41 outfalls. 


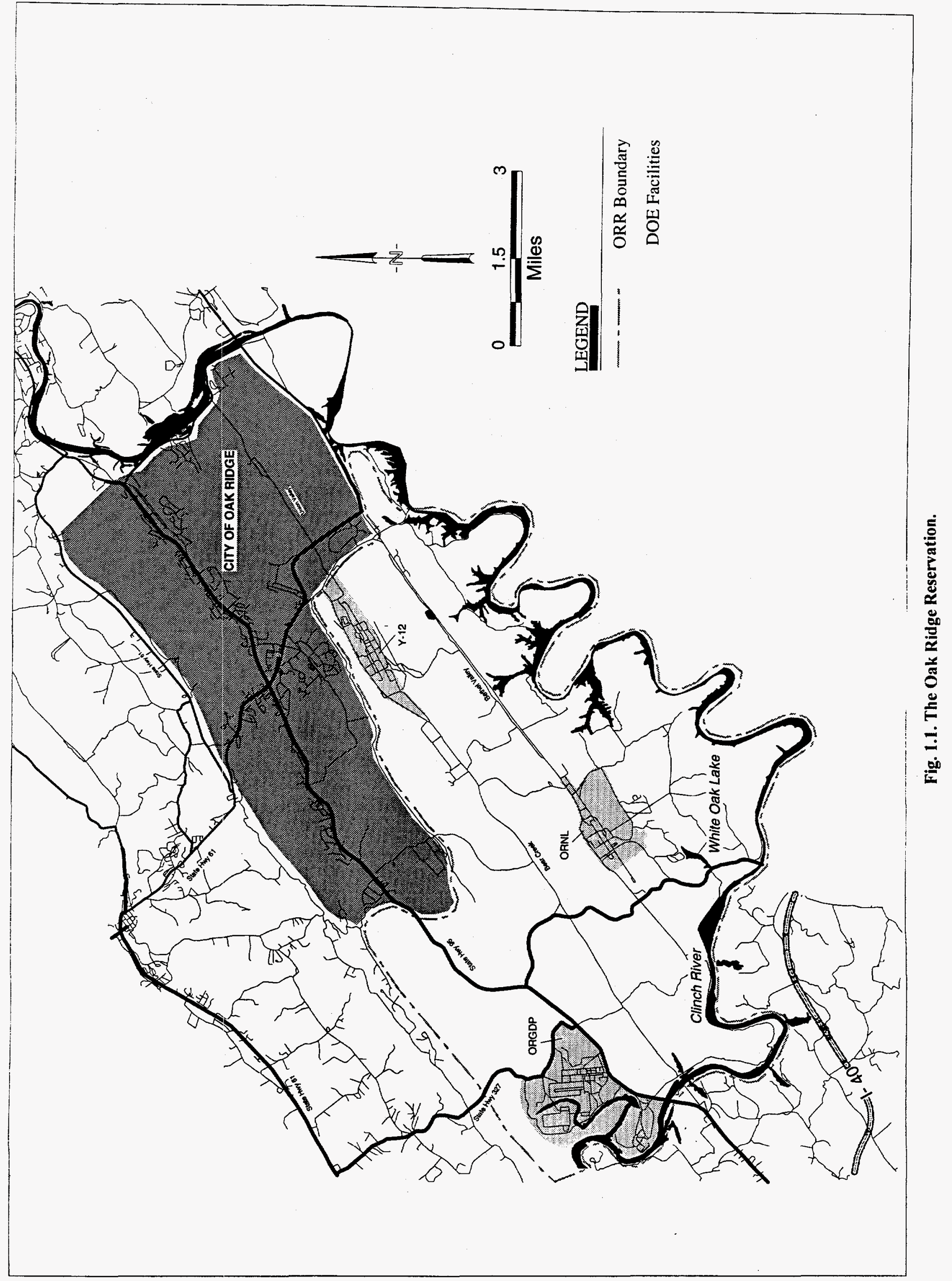




\section{SAMPLING PURPOSE AND SCOPE}

The UEFPC CA RI team has developed a list of key questions related to the characterization of the watershed. The following are two of the key questions:

1. What are site-related contaminant sources, flow paths, and exposure points (present and future)?

2. What is the relative contribution from each sourcelflow path to an exposure point?

The evaluation and assessment of existing data from the CA by the RI team has identified additional data needed to complete the UEFPC CA RI. One of the needs is additional data regarding VOCs in the storm drains, which can be used to determine whether the storm drains are a pathway for contaminated groundwater migration. The data collected from this storm drain sampling will be used to accomplish the following actions:

- provide data to characterize water in the storm drain system and evaluate the impact that the storm drain system may have on the migration of contaminants;

- characterize the nature and extent of groundwater contamination (where storm drains intercept groundwater);

- identify potential sources of contamination;

- clarify storm drain/groundwater interaction;

- determine the need for early actions to mitigate contaminant migration from the storm drain system; and

- provide the data necessary to identify, screen, and develop remedial alternatives, if action is deemed necessary, for the FS.

The purpose of this SAP is to provide a plan for data collection that will determine whether the storm drains are a pathway for contaminated groundwater migration, that is, whether the storm drains are intercepting contaminated groundwater. This information will also provide data relative to the extent of the groundwater contamination and points where contamination discharges to the surface.

The scope of this SAP consists of collecting samples from a minimum of 41 locations in the Y-12 Plant storm drain system and analyze them for the presence of VOCs by using the ion trap mass spectrometer (ITMS) in the field (getting real-time analyses/data). Field analysis with immediate turnaround will reduce costs, including shipping and handling of the samples, and will allow the team to trace any detections up the storm drain. Following detections up the storm drain will result in collection of additional samples and allows for the possibility of locating sources. The 17 VOC contaminants that are potentially site-related contaminants of concern (COCs) are noted in Table 2.1. The quantification goal for these contaminants is $1 \mathrm{ppb}$. Detection limits for the other compounds will be $2 \mathrm{ppb}$ with all detections reported that are above the instrument detection limit and below the quantification limit. Confirmatory samples to be sent to a fixed-base laboratory for analyses will be collected at a frequency of $10 \%$. These samples will be analyzed for all 41 compounds in Table 2.1 .

Sample locations were selected based on several factors. Existing data were used to determine sample locations. Samples collected will be from storm drains that have shown VOC contamination, 
areas where storm drain elevations are close to groundwater elevations (to determine if storm drains are intercepting contaminated groundwater), and other storm drain sampling locations that will assist in determining the extent of VOC plumes that have been previously defined and discharge points to the surface. Samples will be collected at or near the outfalls listed in Table 2.2, and additional sampling will be performed up from these outfalls if initial samples show contamination. Figure 2.1 shows the locations of the outfalls. Sampling will be conducted during the wet season when the water table is elevated and groundwater contributions to the storm drain system are more likely. If a deviation from this SAP occurs because of site conditions, including access problems or a lack of water in an outfall, a field change order request will be initiated. The field change order request will be reviewed and approved by the Y-12 Environmental Restoration project manager or designee.

Table 2.1. Compounds analyzed for in storm drain samples

\begin{tabular}{|c|c|c|c|c|c|}
\hline Compound & $\mathrm{COC}$ & Compound & $\mathrm{COC}$ & Compound & $\mathrm{COC}$ \\
\hline 1,1-Dichloroethane & - & Acetone & - & Dibromochloromethane & \\
\hline 1,1-Dichloroethylene & - & Acetonitrile & & Ethylbenzene & - \\
\hline 1,1,1-Trichloroethane & - & Acrolein & & Ethyl methacrylate & \\
\hline 1,1,2-Trichloroethane & & Acrylonitrile & & Iodomethane & \\
\hline 1,1,2,2-Tetrachloroethane & & Benzene & - & $\begin{array}{l}\text { Methylene chloride (i.e., } \\
\text { Dichloromethane) }\end{array}$ & - \\
\hline 1,2-Dichloroethane & - & Bromodichloromethane & & Styrene & \\
\hline $\begin{array}{l}\text { 1,2-Dichloroethylene } \\
\text { (total), }\end{array}$ & - & Bromoform & & Tetrachloroethene & - \\
\hline 1,2-Dichloropropane & & Bromomethane & & Toluene & - \\
\hline $\begin{array}{l}\text { 1,3-Dichloropropene } \\
\text { (total) }\end{array}$ & & Carbon disulfide & & Xylenes (total) & - \\
\hline 1,4-Dichloro-2-butane & & Carbon tetrachloride & - & Trichloroethene & - \\
\hline 2-Butanone & . & Chlorobenzene & - & Trichlorofluoromethane & \\
\hline 2-Chloroethylvinyl ether & & Chloroethane & & Vinyl acetate & - \\
\hline 2-Hexanone & & Chloroform & - & Vinyl chloride & \\
\hline 4-Methyl-2-pentanone & & Chloromethane & & & \\
\hline
\end{tabular}

Table 2.2. Outfalls to be sampled

\begin{tabular}{rrrrrr}
\hline 2 & 150 & 182 & 195 & 206 & 233 \\
4 & 160 & 183 & 196 & 208 & 234 \\
8 & 163 & 185 & 197 & 221 & 235 \\
34 & 169 & 190 & 201 & 222 & 240 \\
51 & 170 & 192 & 202 & 223 & 502 \\
114 & 180 & 193 & 204 & 224 & 512 \\
147 & 181 & 194 & 205 & 225 & \\
\hline
\end{tabular}




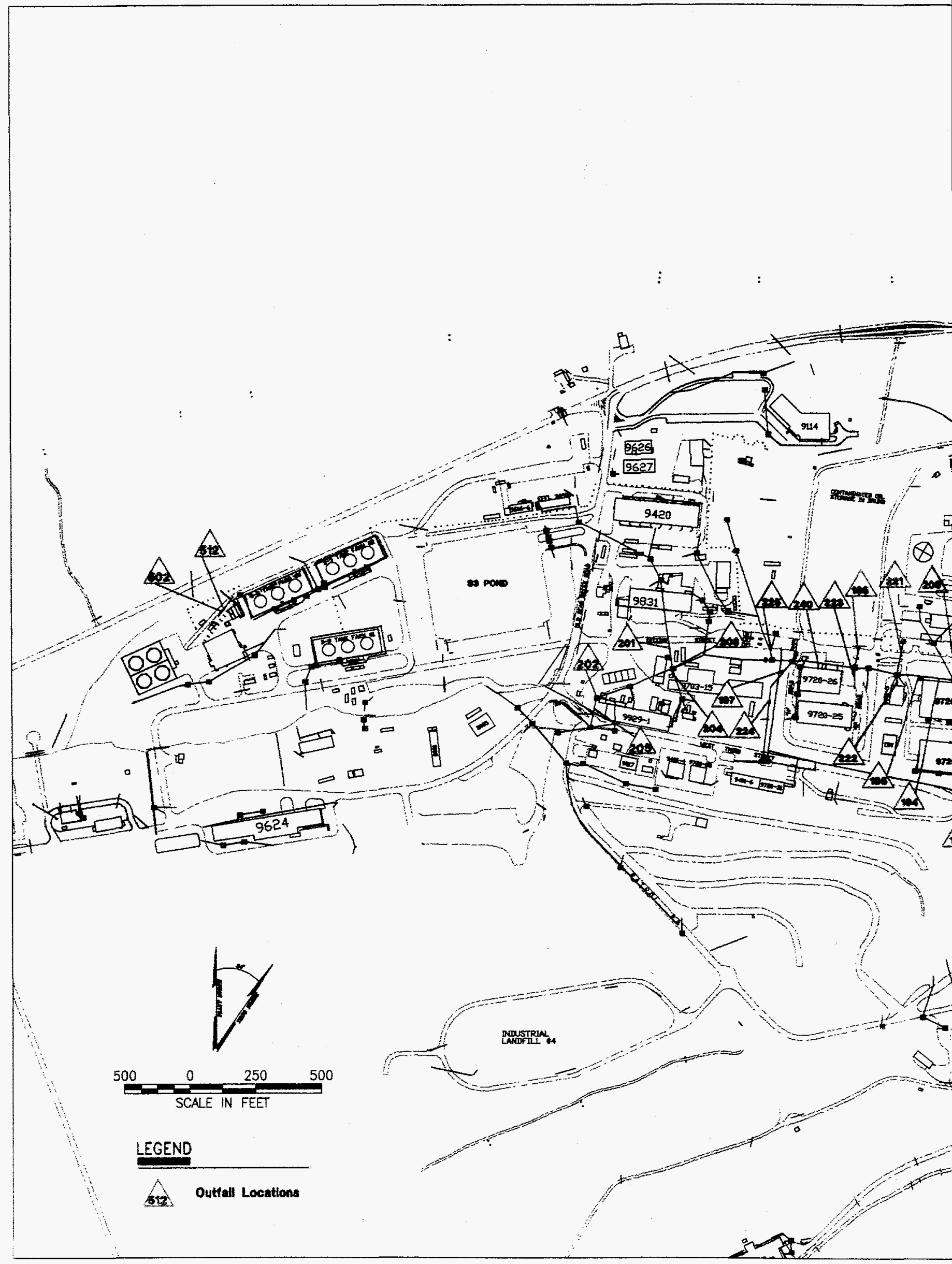

Fig. 2.1. Out 
(panuịud

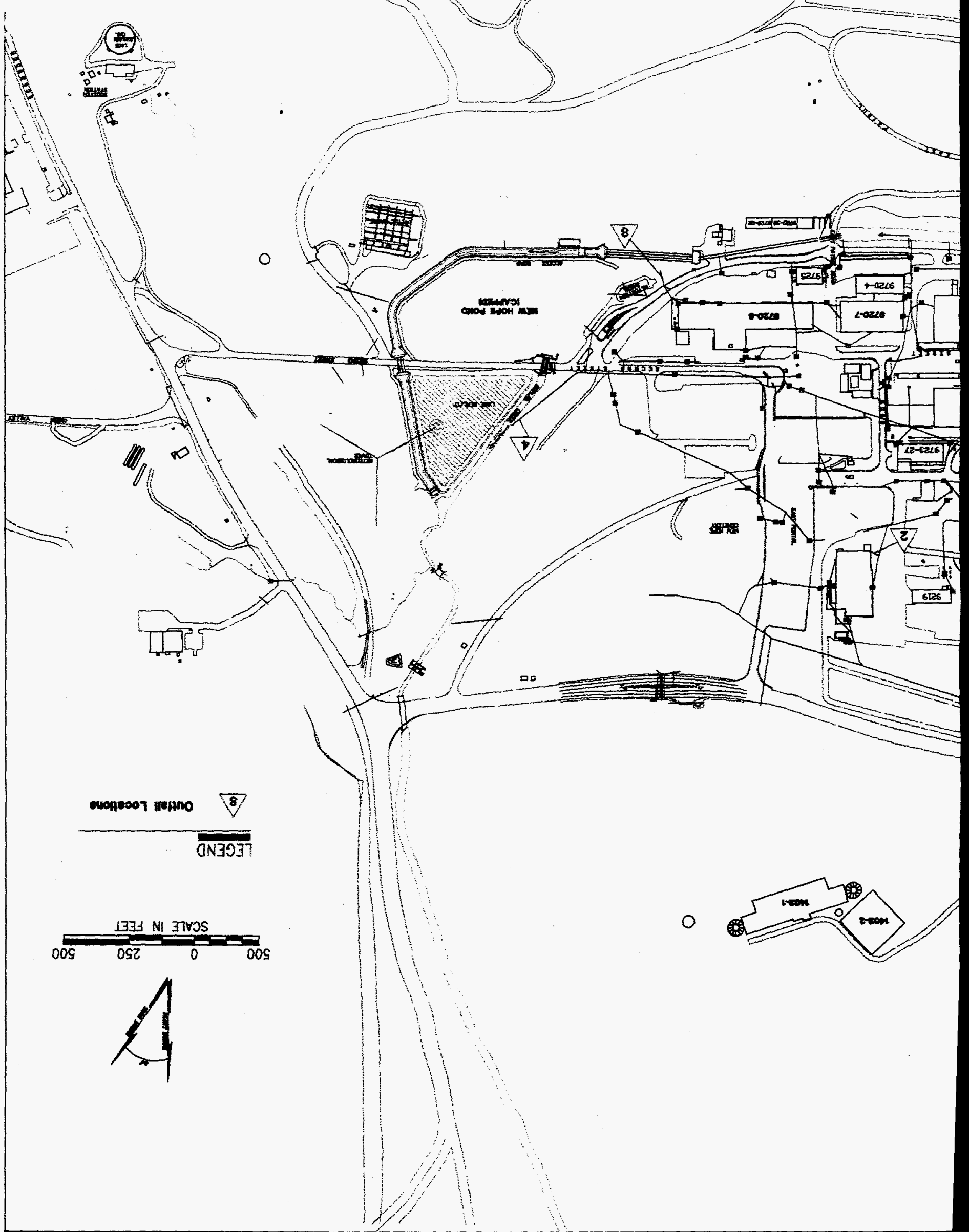




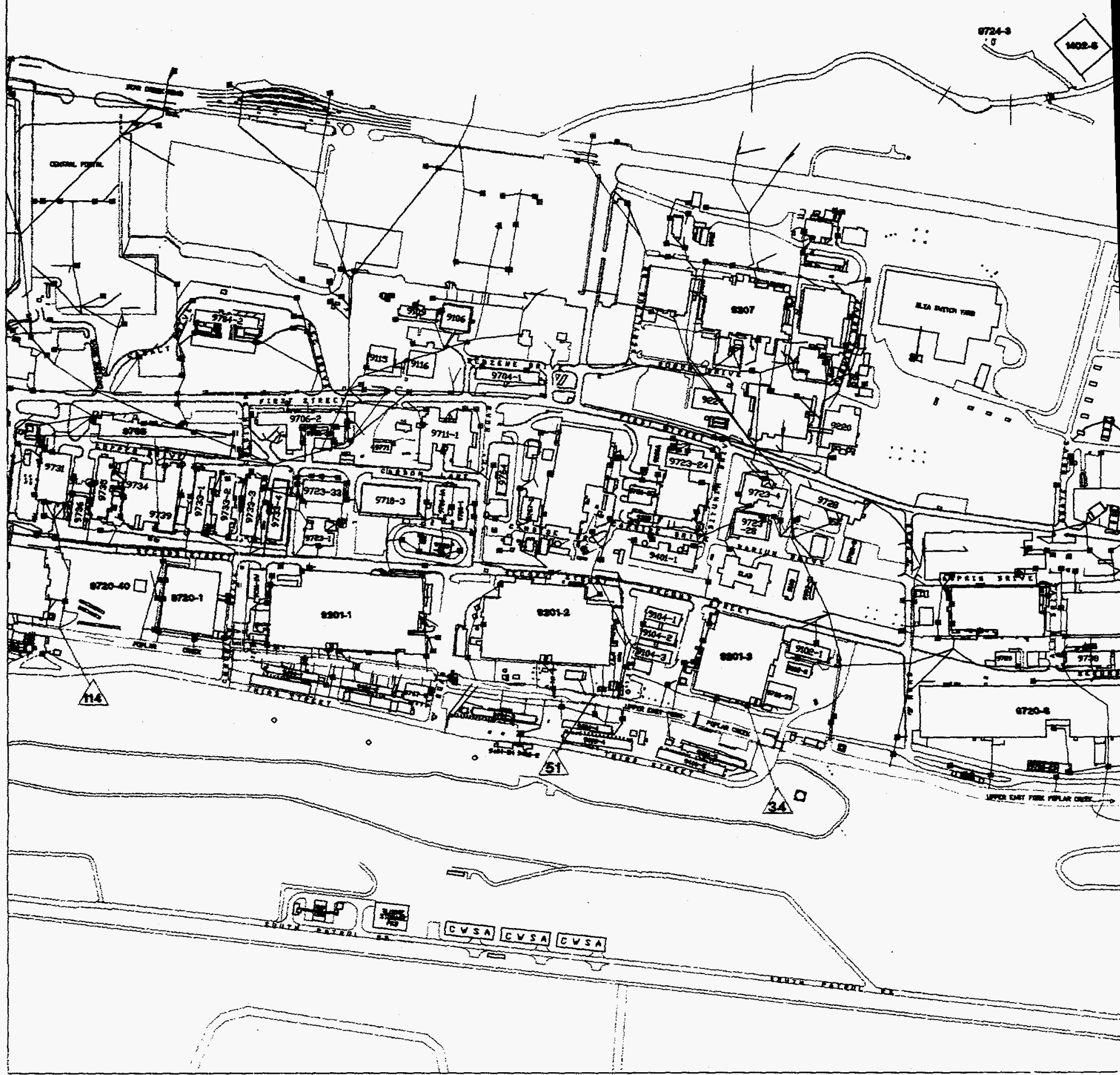

Fig. 2.1. (c 


\section{SAMPLING PLAN}

This section describes the specific sampling and analysis requirements and procedural guidance that will be used to perform sampling and analysis of the VOCs in the storm drains. Fieldwork will be conducted in accordance with this SAP and the Work and Quality Assurance Plan for Research and Development in Support of the Reduction of Mercury in Plant Effluent Program, Y/ER-221 (Energy Systems 1995); any deviations from this SAP will be documented on Y-12 Field Change Request Forms and approved by the Y-12 Project Manager. All field activities will be conducted in accordance with the appropriate Standard Operating Procedures provided in Environmental Surveillance Quality Control Program, ES/ESH/INT-14 (Energy Systems 1988).

\subsection{FIELD TASKS}

Field tasks for this SAP consist of the collection of water samples in the storm drain system for VOC analysis. Personnel from Health, Safety, Environment, and Accountability (HSEA) along with CDM Federal Programs Corporation personnel will perform the sampling tasks, which include filling the pre-labeled sample bottles with grab samples collected in accordance with this SAP and HSEA protocols, preserving the samples, and transporting the samples to the on-site field laboratory for analysis. Samples will be collected directly in standard VOC vials. If access does not allow for collection directly into the vials, the sample will be collected in a glass jar and transferred to the VOC vial following HSEA protocols. Table 3.1 presents the analytical methods, sample volumes, preservation, and minimum number of samples.

Table 3.1. VOC sampling analytical method

\begin{tabular}{|c|c|c|c|c|c|c|}
\hline Analysis & Method & Turnaround time & Sample volume & $\begin{array}{c}\text { Holding } \\
\text { time }\end{array}$ & Preservation & $\begin{array}{c}\text { Number of } \\
\text { samples }\end{array}$ \\
\hline $\begin{array}{l}\text { VOCs by field } \\
\text { laboratory }\end{array}$ & $\begin{array}{l}\text { EPA } 8265 \\
\text { pending }\end{array}$ & $\begin{array}{l}3 \text { days maximum } \\
\text { (1 hour anticipated) }\end{array}$ & $\begin{array}{l}340-\mathrm{mL} \text { glass vials } \\
\text { with Teflon septa }\end{array}$ & 7 days & Cool to $4^{\circ} \mathrm{C}$ & $\begin{array}{c}51 \\
\text { (including } \\
\text { QC samples) }\end{array}$ \\
\hline $\begin{array}{l}\text { VOCs by fixed- } \\
\text { base laboratory }\end{array}$ & EPA 524 & 30 days & $\begin{array}{l}340-\mathrm{mL} \text { glass vials } \\
\text { with Teflon septa }\end{array}$ & 14 days & $\begin{array}{c}\mathrm{HNO}_{3} \text { to } \mathrm{pH}<2 \\
\text { cool to } 4^{\circ} \mathrm{C}\end{array}$ & $\begin{array}{l}7 \text { (including } \\
\text { QC samples) }\end{array}$ \\
\hline
\end{tabular}

The surface water grab samples acquired from the storm drain system will be analyzed on-site by the Analytical Chemistry Division at Oak Ridge National Laboratory. Field personnel will transport the samples under custody from the sampling site to the field laboratory. Sample analysis will be completed by using pending U.S. Environmental Protection Agency (EPA) Method 8265, Direct Sampling ITMS, which can measure 41 organic compounds on the EPA Target Compound List, including the 17 potentially site-related COCs. The pending EPA ITMS method is included as Appendix A. This method has been previously approved by EPA but is pending again at this time due to a slight modification. By using this method, VOCs are vaporized from the sample matrix and introduced into the ion source by a flow of helium where they are ionized by electron and chemical ionization. Full scan mass spectra are acquired that are used to identify and quantify targeted analytes by using characteristic ion masses. The method does not require prior sample preparation or gas chromatograph separation, and results typically are available in less than $\mathbf{3 0}$ minutes. 
The fixed-base laboratory analytical samples will be transported to the Analytical Services Organization laboratory or to on-site CDM Federal Programs Corporation personnel for shipping to an outside laboratory. Laboratory analysis will have a 30-day turnaround time.

\subsection{BEST MANAGEMENT PRACTICES}

Best Management Practices set forth in Best Management Practices for the Y-12 Plant, Y/Sub/92-DGF20V/1 (Energy Systems 1992), and in the Reduction of Mercury in Plant Effluent SAP will be followed.

\section{HEALTH AND SAFETY}

The storm drain sampling has the potential for exposure to a variety of hazards associated with the operation of an industrial facility. The types of hazards that may be encountered are physical, chemical, and radiological in nature. Standard preventive measures, including the exclusion of unnecessary personnel and equipment, will be used to minimize the potential for exposure. All activities will be in compliance with Occupational Safety and Health Administration guidelines, 29 CFR 1910.210, DOE Orders, and Energy Systems' policies and procedures. The Y-12 Plant Radiological Control Organization will determine, in advance of the sampling, if any deviation from posted requirements is needed.

\section{WASTE MANAGEMENT}

Waste management practices used in the storm drain VOC sampling effort will comply with procedures for the Environmental Restoration Program at the Y-12 Plant, Waste Removal and Disposition through the Y-12 ER Program, ER/Y-P2102 (IAD), Rev. 0, and with procedures outlined in Environmental Surveillance Quality Control Program, ES/ESH/INT-14 (Energy Systems 1988).

\section{QUALITY ASSURANCE/QUALITY CONTROL}

The specifications in the Oak Ridge Sample Management Office Analytical Support Agreement (September 9, 1996) and the Environmental Restoration Quality Program Plan, ES/ER/TM-4/R4 (Energy Systems 1994), must be met. Ten percent of the analytical data (all of the data sent for confirmatory analysis to the fixed-base laboratory) will be validated. The laboratory analytical data will be validated in accordance with guidelines contained in the Environmental Restoration and Waste Management Program Intersite Procedures Manual, Procedure No. ERWM/ER-P2210.

\subsection{FIELD QUALITY CONTROL SAMPLES}

All field measuring equipment (i.e., $\mathrm{pH}$, conductivity, temperature) will be calibrated according to manufacturers' instructions. A record of equipment calibration will be maintained as part of the 
field records to provide equipment traceability. The quality control (QC) samples for this project are summarized in Table 6.1. Each ITMS sample will be analyzed twice. Duplicate samples and equipment rinseates (field blanks) will be collected at a frequency of $10 \%$. One field blank will be collected and analzed. Ten percent of the samples will be split and sent to a fixed-base laboratory for VOC analysis. This will provide confirmation of the ITMS field laboratory analyses.

Table 6.1. Summary of field QC samples for sampling of VOCs in storm drains

\begin{tabular}{lccccc}
\hline \multicolumn{1}{c}{ Analyte } & $\begin{array}{c}\text { Number of } \\
\text { samples }\end{array}$ & $\begin{array}{c}\text { Trip blank } \\
\text { (aqueous) }\end{array}$ & $\begin{array}{c}\text { Field blank } \\
\text { (aqueous) }\end{array}$ & Duplicate & Total \\
\hline VOCs - ITMS & 41 & & 1 & 5 & 47 \\
VOCs - Confirmatory samples & 5 & 1 & & 1 & 7 \\
\hline
\end{tabular}

\subsection{LABORATORY QUALITY CONTROL REQUIREMENTS}

Fixed-base laboratory analytical samples will include, as appropriate, the following laboratory QC samples:

- laboratory control samples,

- laboratory duplicates,

- matrix spikes,

- method blanks, and

- $\quad$ surrogate recovery.

\section{DELIVERABLES}

For the analytical data, the field and fixed-base laboratories will provide an electronic data deliverable (in Bechtel Environmental Information Data Management System format) that includes the following information:

- sample identification (ID),

- container ID,

- code identifying laboratory,

- sample delivery group ID,

- lab blank sample ID,

- Chemical Abstracts Service number,

- name of analyte,

- laboratory test code,

- analytical result,

- radiological error, 
- units for result,

- type of laboratory analysis,

: laboratory qualifier,

- validation qualifier,

- date of sample collection,

- time of sample collection,

- date of sample receipt,

- date of sample analysis,

- time of sample analysis,

- code for analytical method,

- code for filtered/unfiltered,

- method detection limit,

- method detection limit units,

- minimum detectable activities (for radionuclides),

- minimum detectable activities units of measure,

- instrument detection limit,

- dilution factor,

- percent moisture,

- code for sample matrix,

- gas chromatography retention time in minutes (tentatively identified compounds only), and

- type of sample.

In addition, all QC samples will be related to the applicable sample delivery group. The laboratory will also provide a data deliverable package (hard copy) of the data. All laboratory deliverables (electronic and hard copies) will be delivered to CDM Federal Programs Corporation for verification and then to the Y-12 Environmental Restoration Data Manager to log in and distribute copies of the data to the project team members. Appendix B contains the data deliverable package requirements for the chemical analyses. If necessary, at the end of the project, the package will be addended to provide any changed information.

\section{SCHEDULE}

The anticipated schedule for the UEFPC CA RI VOC storm drain sampling is presented in Fig. 8.1. Sampling activities are scheduled to begin in March 1997. It is estimated that sampling activities will be completed within 5 working days. At a minimum, the analytical data will be reported electronically within 45 calendar days from the date that the last sample is received by the 


\begin{tabular}{|c|c|c|c|c|c|c|c|}
\hline \multirow{2}{*}{ Task Name } & \multirow{2}{*}{ Duration } & \multirow{2}{*}{ Start } & \multirow{2}{*}{ End } & \multicolumn{4}{|c|}{1997} \\
\hline & & & & Feb & Mar & Apr & May \\
\hline Submit SAP to K-25 DMC & $0.00 \mathrm{~d}$ & Feb/14/97 & Feb/14/97 & $\triangle$ & & & \\
\hline DMC Revision & $5.00 \mathrm{~d}$ & Feb/14/97 & Feb/20/97 & & & & \\
\hline Submit SAP to Regulators & $0.00 \mathrm{~d}$ & Feb/21/97 & Feb/21/97 & $\triangle$ & & & \\
\hline Regulator Review & $10.00 \mathrm{~d}$ & Feb/21/97 & Mar/06/97 & & & & \\
\hline Regulator Approval & $0.00 \mathrm{~d}$ & Mar/07/97 & Mar/07/97 & & $\triangle$ & & \\
\hline Mobilization & $5.00 \mathrm{~d}$ & Mar/10/97 & Mar/14/97 & & 口 & & \\
\hline Sampling & $4.00 \mathrm{~d}$ & Mar/17/97 & Mar/20/97 & & 口 & & \\
\hline Laboratory Analysis & $25.00 \mathrm{~d}$ & Mar/17/97 & Apr/18/97 & & & & \\
\hline Data Validation & $24.00 \mathrm{~d}$ & Apr/21/97 & May/22/97 & & & & \\
\hline & & & & & & & \\
\hline & & & & & & & \\
\hline & & & & & & & \\
\hline & & & & & & & \\
\hline & & & & & & & \\
\hline & & & & & & & \\
\hline & & & & & & & \\
\hline & & & & & & & \\
\hline & & & & & & & \\
\hline & & & & & & & \\
\hline & & & & & & & \\
\hline . & & & & & & & \\
\hline & & & & & & & \\
\hline
\end{tabular}

Fig. 8.1. UEFPC VOCs in storm drains sampling schedule. 
laboratory. The data deliverable package (hard copy) required for analytical data validation will be delivered within 30 days from the date that the last sample is received by the laboratory.

\section{REFERENCES}

Energy Systems (Martin Marietta Energy Systems, Inc.). 1988. Environmental Surveillance Quality Control Program, ES/ESH/LNT-14.

Energy Systems (Martin Marietta Energy Systems, Inc.). 1992. Best Management Practices for the Y-12 Flant, Y/Sub/92-DGF20V/1.

Energy Systems (Martin Marietta Energy Systems, Inc.). 1994. Environmental Restoration Quality Program Plan. ES/ER/TM-4/R4.

Energy Systems (Martin Marietta Energy Systems, Inc.). 1995. Work and Quality Assurance Plan for Research and Development in Support of the Reduction of Mercury in Plant Effluent Program, Y/ER-221.

EPA (U.S. Environmental Protection Agency). 1994. Test Methods for Evaluating Solid Waste, SW-846. 
APPENDIX A

PENDING EPA ITMS METHOD 8265 
DIRECT SAMPLING ION TRAP MASS SPECIROMETRY (DSITMS) RAPID ANALYTICAL METHODS FOR MIASURING THIRTY-FOUR ORGANIC COMPOUNDS ON THE EPA TARGET COMPOUND IIST (TCI) IN WATER, SOIL, AND AIR

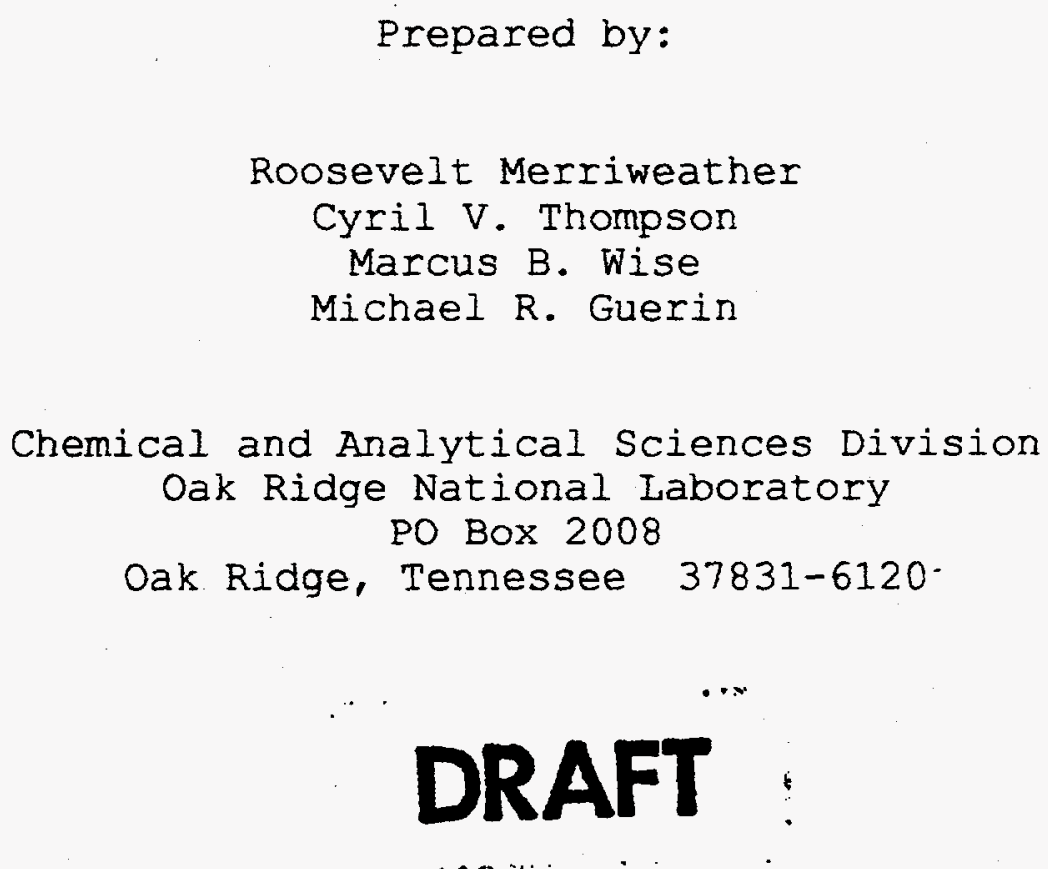

Revised: November 1996 
DIRECT SAMPLING ION TRAP MASS SPECTROMETRY (DSITMS) RAPID ANAIYTICAL METHODS FOR MEASURING THIRTY-EOUR ORGANIC COMPOUNDS ON THE EPA TARGET COMPOUND IIST (TCL) IN WATER, SOIL, AND AIR

\subsection{SCOPE AND APPLICATION}

1.1 Method 8265 describes quick, cost-effective analytical procedures for the detection and measurement of volatile organic compounds (VOCs) in water, soil, and air samples using Direct Sampling Ion Trap Mass spectrometry (DSITMS). This method allows analysis of samples containing volatile organic compounds at concentrations of $25 \mathrm{ng} / \mathrm{ml}$ in water, $\cong 5 \mathrm{ug} / \mathrm{kg}$ in soil (performance may be affected by soil type), and $\cong 50$ ppbv in air (realtime) and $>5$ ppbv (off-line). The following compounds can be determined by this method:

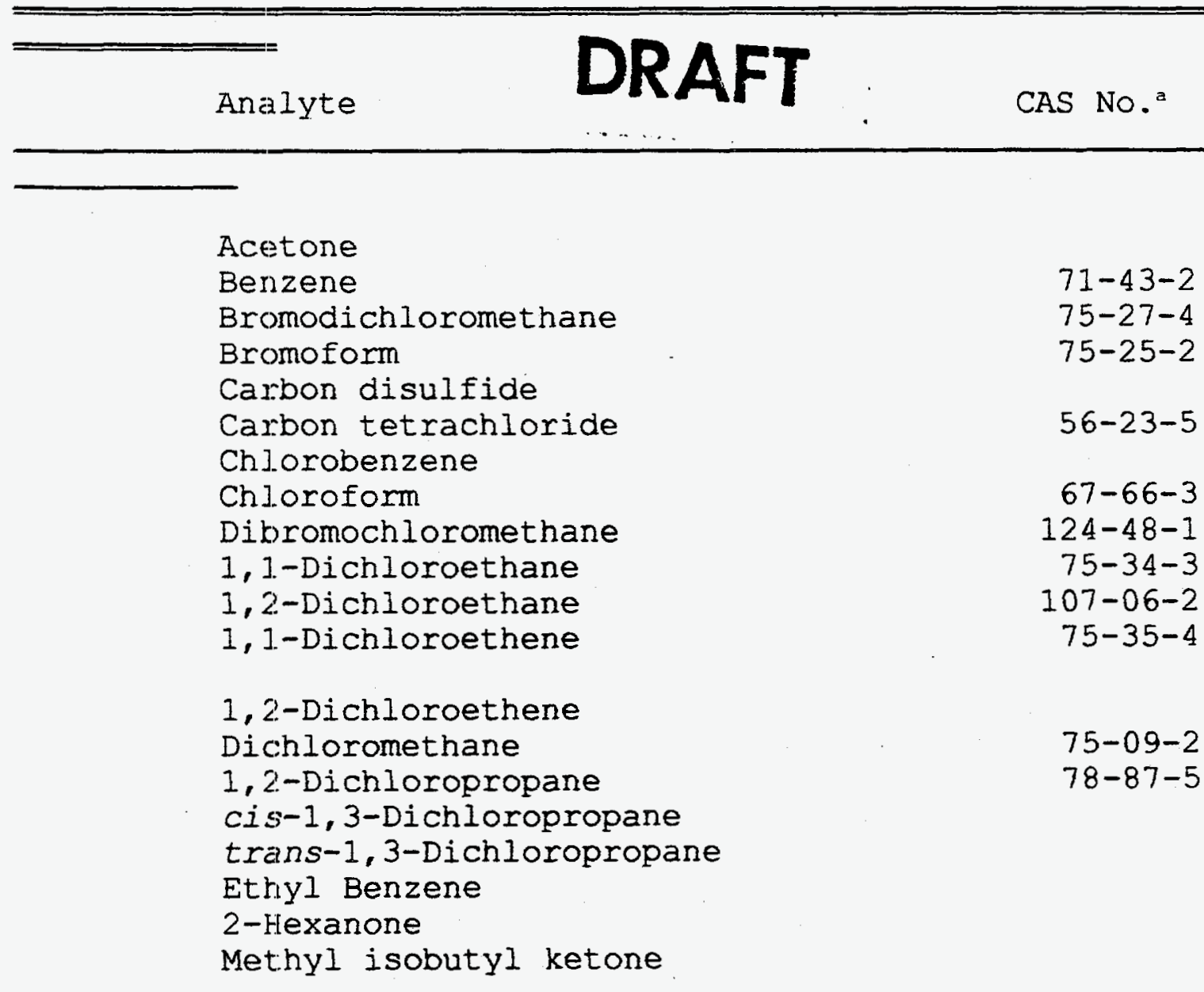


Methyl ethyl ketone

Styrene

$1,1,2,2$-Tetrachloroethane

Tetrachloroethene

$79-34-5$

Toluene

$127-18-4$

1,1,1-Trichloroethane

1, 1,2-Trichloroethane

$71-55-6$

Trichloroethene

Vinyl Acetate

$79-00-5$

Total xylenes

1.2 Additional volatile organic compounds can be determined by this method provided that acceptable detection limits can be established using standards prepared from authentic compounds and one or more unique ions can be identified for measurement purposes.

\subsection{SUMMARY OF METHODS}

2.1 These methods employ custom-built sampling units such as water sparge, air sampling, atomizing continuing water monitoring, in situ water monitoring, and direct push soil sampling that interface directly with the ITMS. The volatile organic analytes are vaporized from the sample matrix and swept into the ion source by means of a flow of helium where they are ionized by electron ionization (EI) and chemical ionization (CI). Full scan mass spectra are acquired which are used to identify and quantitate targeted analytes using characteristic ion masses (mass-to-charge or $\mathrm{m} / \mathrm{z}$ ). The direct push soil sampling technique, unlike the others, consists of a thermal desorption sampling probe (TDS) that is pushed to the depth of interest using a cone penetrometer truck. Once the depth of interest is reached, an interior piston in the sampler is retracted. and a soil sample is collected. The sample is heated and nitrogen is used as the carrier gas to transport the volatilized voCs to the surface via a transfer line to a sorbent trap. The analytes are thermally desorbed from the sorbent trap and then transported into the ion trap by helium flow, as mentioned above. The analytes are detected and quantitated in real time using direct sampling ion trap 
mass spectrometry.

2.2 Thjs procedure permits data to be acquired in both EI and CI modes, alternating one to the other under computer control. In the EI mode, structural information is obtained from the fragmentation pattern produced, while complementary molecular ion information is obtained in the CI mode. The CI mode also provides enhanced sensitivity and improved selectivity for certain compounds including alkyl-aromatics, ketones, and aldehydes. 
3.1 Volatile compounds in the samples yielding ions with the same $\mathrm{m} / \mathrm{z}$ values as the characteristic ions of the targeted VOCs will give a false positive response in this analytical method. For samples analyzed yielding a positive response confirmatory analysis should be obtained. Also, some vocs cannot be unequivocally distinguished using this method, such as cis \& trans isomers and other compounds yielding identical characteristic ions.

\subsection{APPARATUS}

\subsection{Analysis of Water}

4.1.1 ITMS (ion trap mass spectrometer) such as Finnigan MAT ITMS (San Jose, CA) or Teledyne 3-DQ (Mountain View, CA) which is capable of operation in CI and EI modes.

4.1.2 Heated, deactivated fused-silica capillary restrictor direct sampling interface with built-in splitter and quick connect fitting for sampling modules. Contains $24 \mathrm{~cm}$ of 100 micron id capillary and can be heated to a maximum temperature of 300C. Can be obtained from Teledyne Electronic Technologies (Mountain View, $C A$ ) or Oak Ridge National Laboratory loak Ridge, TN).

4.1.3 Precalibrated variable volume pipets that are compatible with methanol or other organic solvents. Polymerase Chain Reaction (PCR) pipet Tri-Continent Scientific, Inc. (TCS) (Gross Valley, $C A$ ) or equivalent.

4.1.4 Syringe, $10 \mu L$ capacity. Precision Sampling (Baton Rouge, I.A) model or equivalent.

4.1.5 Screw cap vials, $5 \mathrm{~mL}$ capacity, pre-cleaned according to existing EPA protocols. Use solid caps containing fixed Teflon liners $\$$ (see Reference 2 under section 10.0).

4.1.6 Screw-cap VOA vials, $40 \mathrm{~mL}$, pre-cleaned according to existing EPA protocols (see 
Reference 2 under section 10.0 ).

4.1.7 Volumetric flask, $10 \mathrm{~mL}$ Pyrexe, (Corning, NY) or equivalent.

4.1.8 Flow meter capable of measuring $100 \mathrm{~mL} / \mathrm{min}$. A.P.Buck Calibration Meter, Model M-5 (Orlando, EL) or equivalent.

4.1.9 Custom-built direct sampling units for analyzing water.

4.1.9.1 For the analysis of water in $40 \mathrm{ml}$ VOA vials, a direct sparging device is used. Can be obtained from Teledyne Electronic Technologies (Mountain View, California) or from Oak Ridge National Laboratory (Oak Ridge, TN).

4.1.9.2 For the analysis of water from a continuously flowing source, such as a process stream, an atomizing continuous water monitor probe is used. Can be obtained from Oak Ridge National Laboratory (Oak Ridge, TN).

4.1.9.3 For In-situ monitoring of water in groundwater or surface water, an In-situ sparger is used. Can be obtained from Oak Ridge National Laboratory (Oak Ridge, TN) .

4.1.10 Stopwatch, laboratory timer, or wristwatch with alan. Must be capable of timing 3 minutes.

\subsection{Analysis of Soil}

4.2.1 ITMS described in section 4.1 .1 .

4.2.2 Need apparatus described in section 4.1.34.1 .9 .1 .

4.2.3 Electronic weighing balance capable of weighing to the nearest tenth of a gram. Allied Fisher Scientific balance, Model $8301 \mathrm{~A}$ (Denver, Colorado) or equivalent. 
4.2.4 Portable heater (for sample vials) capable of reaching a temperature range between $140-$ $200^{\circ} \mathrm{F}$. Omega Engineering heater, Model

CN9000A (Stanford, CT) or equivalent.

4.2.5 Aluminum sleeve $0.5 \mathrm{~cm}$ in thickness, $5.5 \mathrm{~cm}$ in length, and $2.8 \mathrm{~cm}$ ID. Oak Ridge National Laboratory (Oak Ridge, Tennessee). Used as a heating jacket for $40 \mathrm{ml}$ VOA vials.

4.2.6: Thermocouple, Omega Engineering (Stamford, CT). Attached to aluminum sleeve for monitoring vial temperature.

4.2.7 Digital Thermometer, Model HH81, Omega Engineering (Stamford, CT) or equivalent. Used to monitor vial temperature

4.2.8 Magnetic stirrer, Model 15, Arthur H. Thomas Co. (Philadelphia, PA) or equivalent.

4.2.9 Stirring bar approximately $0.8 \mathrm{~cm}$ in thickness and $2 \mathrm{~cm}$ in length.

4.2.10 Standard 20 ton cone penetrometer vehicle equipped with hydraulic rams capable of advancing and retracting up to 2 inch outer diameter steel push pipe into subsurface soils and including hot water/steam cleaner decontamination equipment. A detailed description of standard cone penetrometery procedures can be obtained by consulting ASTM Method D-3441 (American Standard Testing Methods, 1995 Annual book of ASTM standards. 04.08 (D-3441), American Society for Testing and Materials, Philadelphia).

4.2.11 Thermal desorption VOC sampling probe (developed and provided by USAE-WES).

4.2.12 Manifold to regulate direction of carrier gas and operation of TDS probe (developed and provided by USAE-WES) .

4.2.13 Power supply to regulate temperature in sample chamber of thermal desorption VOC probe. 
4.3 Analysis of Air

4.3.1 ITMS described in section 4.1.1.

4.3.2 Custom-built real-time air sampling unit can be obtained from Teledyne Electronic Technologies (Mountain View, California) or from Oak Ridge National Laboratory (Oak Ridge, TN) .

4.3.3 Tedlar@ gas sample bags, 10 and 20 liter capacity (SKC Inc, Eighty Four, PA)

4.3.4 Syringe, $2000 \mathrm{ml}$ capacity, Hamilton Co. (Reno, Nevada) or equivalent

4.3.5 Air-tight syringe, 1, 5, 25, and $50 \mathrm{ml}$ capacity, Hamilton Co. (Reno, Nevada)

4.3.6 Thermal desorber capable of accepting 0.25 in (diameter) by 3 in (length) sorbent tubes. Can be obtained from Teledyne Electronic Technologies (Mountain View, California) or Oak Ridge National Laboratory (Oak Ridge, TN).

4.3.7 Variac or timer-type heater controller for thermal desorber.

4.3.8 Digital thermometer at described in section 4.2 .7 .

4.3.9 Stopwatch, laboratory timer, or wristwatch as described in section 4.1 .10

\subsection{REAGENTS}

\subsection{Water and Soil Standards}

5.1.1 Reagent grade chemicals shall be used in all tests. Unless otherwise indicated, it is intended that all reagents shall conform to the specifications of the comnittee on Analytical Reagents of the American Chemical Society, where such specifications are available. Other grades may be used, provided

$$
\text { 8265-8 Revision WG }
$$


it is first ascertained that the reagent is of sufficiently high purity to permit its use without lessening the accuracy of the determination

5.1.2 Water, US Army Environmental Center (USAEC) simulated groundwater prepared by adding 148 $\mathrm{mg} / \mathrm{L}$ of sodium sulfate and $165 \mathrm{mg} / \mathrm{L}$ of sodium chloride (100 $\mathrm{mg} / \mathrm{L}$ each of $\mathrm{SO}_{4}^{--}$and $\mathrm{Cl}$ ions) to ASTM Type II water from a Milli-Q® unit or equivalent as defined by Rocky Mountain Arsenal Chemical Quality Assurance Plan, Version 1.0, July, 1989, pp. 4-7.

5.1.3 Methanol, $\mathrm{CH}_{3} \mathrm{OH}$ - HPIC or "purge and trap" grade, or equivalent, demonstrated to be free of analytes. Store apart from other solvents.

5.1.4 Helium 99.9999\% minimum purity such as Research Grade Alphagaz (walnut Creek, CA) or equivalent.

5.1.5 Neat volatile materials, $99 \%$ purity.

5.1.5.1 Materials may be purchased as dilute solutions of known concentrations in methanol, shipped and stored in ampules, and substituted for neat target chemicals. (Bellefonte, PA), or NSI Environmental Solutions, Inc. (Research Triangle Park, NC) or equivalent.

5.1.6 Stock solutions of individual target analytes

5.1.6.1 For individual neat liquid analytes

5.1.6.1.1 Dilute sufficient amount of analyte in a $10 \mathrm{~mL}$ volumetric flask with methanol to yield $5000 \mathrm{\mu g}$ analyte/mL solution ( $5 \mu \mathrm{g} / \mu \mathrm{L}$ ). The volumes of neat liquid analyte or the thirtyfour target volatile analytes specified by the U.S. Environmental Protection Agency needed for this task specified in Table 3 .

5.1.6.1.2 Transfer the solution prepared in Section 5.1.6.1.1 to a $5 \mathrm{~mL}$ capacity 
screw-cap vial. This is the "master stock solution" for the analyte.

5.1.6.1.3 Dilute exactly 200 uL of the master stock solution prepared in section 5.1 .6 .1 .1 to $10 \mathrm{~mL}$ in a volumetric flask with methanol. The resulting final concentration is $100 \mathrm{\mu g}$ analyte/mL solution or $0.1 \mu \mathrm{g} / \mu \mathrm{L}$.

5.1.6.1.4 Transfer this solution to a $5 \mathrm{mI}$ capacity screw-cap vial. This is the "working stock solution" for the analyte. Store in a freezer maintained between -10 to $20^{\circ} \mathrm{C}$.

5.1.6.1.5 The lifetime of the "master" solution is about 6 months; that of the "working" solution is about 2 weeks when stored as described.

5.1.6.2 For individual analytes available in $1 \mathrm{~mL}$ ampules containing $1 \mathrm{~mL}$ of $1000 \mathrm{\mu g}$ analyte/mL methanol solution.

5.1.6.2.1 Dilute the contents of the ampule with methanol to exactly $10 \mathrm{mI}$ final volume in a volumetric flask. The final concentration is $100 \mu \mathrm{g} / \mu \mathrm{L}$.

5.1.6.2.2 Transfer the solution prepared in Section 5.1.6.2.1 to a $5 \mathrm{~mL}$ capacity screw-cap vial. This is the "working stock solution" for the analyte. Store in a freezer maintained at -10 to $-20^{\circ} \mathrm{C}$.

5.1.6.2.3 The shelf life of the "working" solution is about 1-2 weeks when stored as described.

5.1.6.3 For individual fixed gas analytes in $1 \mathrm{~mL}$ ampules containing $1 \mathrm{~mL}$ of $1000 \mathrm{\mu g} / \mathrm{mL}$ analyte/mL methanol solution.

5.1.6.3.1 Dilute the contents of the ampule with methanol to exactly $10 \mathrm{mI}$ final volume in a volumetric flask. The 
final concentration is $100 \mathrm{ug}$ analyte/mL solution, or $0.1 \mathrm{\mu g} / \mathrm{ul}$.

5.1.6.3.2 Transfer the solution prepared in Section 5.1.6.3.1 to two $2 \mathrm{~mL}$ capacity screw-cap vials without headspace. Discard the excess stock solution. This is the "working" stock solution for the analyte. Store in a freezer maintained at -10 to $-20^{\circ} \mathrm{C}$.

5.1.6.3.3 The shelf Iife of the "working" stock solution for fixed gas analytes is about one week.

5.1.7 Performance Evaluation Check Standard

5.1.7.1 Master Stock Solution

5.1.7.1.1 Dilute $101.1 \mu \mathrm{L}$ acetone, $120.8 \mu \mathrm{L}$ methylene chloride, $45.8 \mu \mathrm{L}$ benzene, and $26.8 \mu \mathrm{L}$ bromobenzene to exactly $10 \mathrm{~mL}$ in methanol using a volumetric flask.

5.1.7.1.2 Transfer the Master Stock Solution to a $20 \mathrm{~mL}$ screw-cap vial with a solid TeflonIined@ cap. Store in a freezer at -10 to $-20^{\circ} \mathrm{C}$.

5.1.7.1.3 Replace the Master Stock Solution every six months.

\subsubsection{Working Stock Solution}

5.1.7.2.1 Dilute $500 \mathrm{\mu L}$ of the Master Stock Solution to exactly $10 \mathrm{~mL}$ with methanol in a volumetric flask to form the Performance Evaluation Sample stock solution. Transfer the Performance Evaluation Sample stock solution to a 5 $\mathrm{ml}$ screw-cap vial with a solid TeflonIined\& cap. Store in a freezer maintained between -10 to $-20^{\circ} \mathrm{C}$.

5.1.7.2.2 Replace the Performance Evaluation Sample stock solution every two to three weeks. 
5.1.8.1 Internal Standard Master Stock Solution

5.1.8.1.1 Dilute $42.8 \mu l$ of 1,4 -diflurobenzene to exactly $10 \mathrm{ml}$ with methanol in a volumetric flask to make a $5000 \mu \mathrm{g} / \mathrm{ml}$ solution.

5.1.8.1.2 Transfer the Master Stock Solution to a 5 ml capacity screw-cap vial with a Teflonlined( cap. Store this solution in a freezer maintained between -10 to $-20^{\circ} \mathrm{C}$.

5.1.8.2 Internal Standard Working Solution

5.1.8.2.1 Dilute $400 \mu \mathrm{I}$ of the Master Stock Solution to exactly $10 \mathrm{mI}$ with methanol in a volumetric flask to make a final concentration of $200 \mu \mathrm{g} / \mathrm{ml}$ solution.

5.1.8.2.2 Transfer the Working Solution to a $5 \mathrm{ml}$ capacity screw-cap vial with a Teflonlined@ cap. Store this solution in a freezer maintained between -10 to $-20^{\circ} \mathrm{C}$. 
5.2 Air Standards

5.2.1 Use the same neat chemicals described in section 5.1 .1

5.2.2 Compressed breathing air, Liquid Air Corporation (Walnut Creek, Ca) or equivalent.

5.2.3 Helium as described in section 5.1.4.

5.2.4 Stock Air Standard

5.2.4.1 Dilute enough of the neat compound in a 20 liter Tedlar@ bag of air to make a 1000 ppmv stock. See formula in section 7.4.1.2 for analyte stock preparation.

5.2.5 Working Standards

5.2.5.1 Dilute enough of the stock standard in 10 liter Tedlar $\otimes$ bag of air to make calibration standards ranging from 10$1000 \mathrm{ppbv}$. See Table 11 for the exact amount of stock to prepare these standards.

6.0 STORAGE, PRESERVATION, AND PREPARATION OF SAMPLES

6.1 See the introductory material to this chapter, Organic Analytes, Section 4.1.

7.0 PROCEDURE

7.1 Daily instrument operational checks

7.1.1 Check and adjust (if necessary) the RF tune (dip) and linearity according to the appropriate instrument operating manual.

7.1.2 Check and adjust (if necessary) the integrator offset (zero) according to the appropriate instrument operating manual.

$8265-13$

Revision WG 
7.1.3 Check vacuum pump rotational speed for normal operation according to the appropriate instrument manual.

7.1.4 Check for normal operation of internal power supplies using built-in instrument diagnostic program if available.

7.1.5 Install the appropriate sample inlet and check the background mass spectrum for excessive air, water, or organic contamination.

7.1.6 Calibrate the ion trap mass axis using an acceptable calibration compound such as perfluorotributylamine (PFTBA). Record the results of the calibration for future reference.

\subsection{Measurement of vocs in water}

7.2.1 Direct purge of $40 \mathrm{ml}$ VOA vials

7.2.1.1 Fill $40 \mathrm{~mL}$ VOA vials to within 1/4" of the lip with AEC water and add $10 \mu \mathrm{l}$ of the Working Internal Standard prepared in section 5.1 .8 .2 .

7.2 .1 .2

Set up the mass spectrometer data acquisition program for the analysis of a single sample (see Table 2 for an example of key sequence program for Finnigan ITMS).

$7 \cdot 2 \cdot 1.3$

Set the acquisition time to 3.0 minutes. If using the ITMS program TTBTX, set loop count to 45 , providing approximately 3.5 minutes of sparging/data collection time.

7.2 .1 .4

Set scan function of DSF (see Table 1 for description of scan function). For non-Finnigan ion traps, an equivalent scan function for alternating EI/CI data acquisition my be used. 

7.2 .1 .5
7.2 .1 .6
Set helium purge flow rate to $100 \pm$ $5 \mathrm{~mL} / \mathrm{min}$ using the flow control valve on the sparge unit. The flow rate is measured using a Buck Calibration Meter.
7.2 .1 .7
Attach the water blank vial specified in Section 7.2.1.1 to the sparging head. See Figure 1 for purge module schematic.
7.2 .1 .8
Execute data acquisition program (TTVBTX if using the Finnigan ITMS). Turn on sparge gas flow and sparge the sample for the full 3.5 minute.
7.2 .1 .9
When data acquisition terminates, switch the gas flow to "off". Replace the sample with an empty 40 mL vial.

7.2.1.10 Analyze results only if there is an EI/CI response for the characteristic ions of the analyte of interest:"

7.2.1.11 Set up data acuisition as in 7.2.1.1 to run the performance Evaluation Sample (PES).

7.2.1.12 Spike a $40 \mathrm{~mL}$ blank water sample, described in section 7.0, with $10 \mu \mathrm{L}$ of the Performance Evaluation Sample Stock solution. Attach the sample to the sparging head.

7.2.1.13 Execute data acquisition program (TTVBTX if using Einnigan ITMS). Turn sparge gas on and sparge the sample for the full 3.5 minutes. This is the initial Performance Evaluation Sample for the working day.

7.2.1.14 When data acquisition terminates, turn the gas flow to "off". Replace the sample with an empty $40 \mathrm{~mL}$ vial. 
7.2.1.15 Evaluation of PES data should fall within 2 standard deviations of the mean value of the peak area for the analytes in the PES sample. If not, do not run samples until this problem is resolved. The solution to this problem may be as simple as making up a fresh PES.Troubleshooting the instrument should be the last resort. Refer to the Instrument Operation Manual for troubleshooting (see Reference 1 under section 10.0 ).

7.2.1.16 The PES should be evaluated at the beginning of the day. Additional PES may be run at any random point during the working day if desired.

7.2.1.17 Set up the data acquisition program (TTVBTX if using Finnigan ITMS) program to analyze 4 replicates of a single concentration. Use scan function DSE or equivalent.

7.2.1.18 Set the loop count to 250, providing approximately $18 \mathrm{~min}$ of sparging/data collection time.

7.2.1.19 Identify the file by whatever convention for the analyte of interest.

7.2.1.20 Add a sufficient aliquot by syringe of the working stock solution of the desired analyte to the sample vial to obtain a solution in the desired concentration range. For example, see Table 4. Add 10 $\mu l$ of the "working" internal standard to the sample. Attach sample to the custom sparging head.

7.2.1.21 Start data acquisition program (TTVBTX if using the Finnigan ITMS). Switch the gas flow to include the sample vial and sparge the sample for exactly three minutes. (use the elapsed time feature on the ITMS, a stopwatch, laboratory timer, or wristwatch with alarm to time this.) 
7.2.1.22 After the sample has been sparged for three minutes, switch the gas flow to bypass the sample vial. Prepare the next sample and attach the vial to the sparging head. Switch the gas flow to include the sample vial in the gas stream. Purge the sample for exactly three minutes.

7.2.1.23 Repeat Section 7.2.1.22 two more times, yielding four replicates at $x$ ng analyte/mL water. After the last sample has been sparged, switch the gas flow to bypass the sample vial, remove the latter from the custom sparging head and replace it with an empty vial.

7.2.1.24 Analyze results for each sample. Refer to Section 7.5 for data reduction and Table 10 for typical calibration curves.

7.2.1.25 Set up the data aquisition to analyze single environmental sample using scan function DSF or equivalent.

7.2.1.26 Set the loop count to 45 providing approximately 3.5 minutes of sparging/analysis time.

7.2.1.27 Identify the file by whatever convention is convenient.

7.2.1.28 Obtain unknown samples. Open the sample vial; remove $2-3 \mathrm{~mL}$ to allow a headspace of ca. 1/4" at the top of the vial. Attach vial to sparge unit.

7.2.1.29 Execute data acquisition program (TTVBTX if using the Einnigan ITMS). Switch the gas flow to include the sample vial. Sparge the sample for the full 3.5 minutes with helium flowing at $100 \pm 5$ $\mathrm{mL} / \mathrm{min}$.

7.2.1.30 When data acquisition terminates, switch the gas flow to exclude the sample vial. Replace the sample with an empty $40 \mathrm{~mL}$ vial. 
7.2.1.31 Refer to Section 7.5 for data reduction and calculation of unknown concentration.

7.2.2 In Situ Sparge

Note: This procedure is used for the direct

measurement of voCs in groundwater without withdrawing a liquid sample from the well.

7.2 .2 .1

The location and depth for each Hydropunch II at any particular site are based on previous site knowledge. Factors to be considered include subsurface geology, known depth to groundwater, hydraulic conductivity, groundwater gradient, and source of VOC contamination, if known.

$7.2 \cdot 2.2$

Advance Hydropunch II predetermine maximum depth below ground surface and record depth.

7.2 .2 .3

Retract penetrometer push-pipe to a maximum of $4 \mathrm{ft}$ to expose well screen for groundwater sampling (see Figure 2). Measure distance'push pipe was retracted and record. It should be noted that the Hydropunch II IM screen can be exposed from a few inches to a maximum of $4 \mathrm{ft}$. depending on the vertical resolution of groundwater sampling desired.

7.2.2.4 Measure depth to groundwater using the conductivity probe and record. Wait 5 minutes and repeat. Repeat at 5 minute intervals until groundwater level in Hydropunch II ${ }^{\mathrm{M}}$ Record final depth to groundwater.

7.2 .2 .5

Once groundwater depth is constant in the Hydropunch II $I^{\mathrm{M}}$, proceed with in situ sparging as specified in $7.2 .2 .6-7.2 .2 .8$ below.

7.2.2.6 Check and calibrate direct sampling 
ion trap mass spectrometer as specified in section 7.1 .

7.2 .2 .7

$7 \cdot 2 \cdot 2 \cdot 7.1$

$7.2 .2 \cdot 7.2$

$7 \cdot 2 \cdot 2 \cdot 7.3$

7.2 .2 .7 .4
Calibration

Set up data acquisition program. Use either an EI or alternating EI/CI scan function as appropriate for the analytes of interest. Acquistion time should be approximately 30 minutes.

Insert in-situ sparge into a $250 \mathrm{ml}$ beaker of distilled water and start data acquisition.

After instrument response has stabilized, insert insitu sparge into a $250 \mathrm{ml}$ beaker containing the low level standard. Leave sparger in place until instrument response is stable. Remove and decontaminate with distilled water.

Repeat section 7.2.2.7.3 for as many different levels of calibration desired. Upon completion of calibration, manually stop the data acquistion program and close the data file.
7.2 .2 .8

7.2 .2 .8 .1

7.2 .2 .8 .2
Data acquisition (unknowns)

Set up acquisition program.

Run time should be at least 20 minutes.

Insert in-situ probe into a $250 \mathrm{ml}$ beaker of distilled water to acquire a baseline 


response. Begin data
acquisition and allow
instrument response to
stabilize.
Lower in situ sparge module to
the groundwater surface at the
depth measured in 7.2 .2 .4$.
Lower until the conductivity
meter on the in situ sparge
module indicates that the
module is at the proper depth
in the groundwater. See Figure
2 for a schematic diagram of
the in situ sparge module.


$7.2 \cdot 2 \cdot 8 \cdot 3$

Monitor voC analyte response until the response is stabilized. Continue to monitor for at least 1 minute.

$7.2 .2 .8 \cdot 4$

Retrieve in situ sparge module and rinse with distilled water.

$7.2 \cdot 2 \cdot 8 \cdot 5$

Insert in-situ sparge into a $250 \mathrm{ml}$ beaker of distilled water. Analyze a blank water sample for baseline response.

$7.2 .2 \cdot 8 \cdot 6$

After instrument response for the blank has stabilized for at least 1 minute, manually stop the data acquisition program and close the data file.

7.2.2.9 Retract Hydropunch II $I^{\text {M }}$ and push pipe. Decontaminate the Hydropunch IIM $^{\mathrm{TM}}$ and push pipe using a hot water/steam cleaner.

7.2.2.10 Reduce data as described in section 7.5.

7.2.3 Atomizing, Continuous Water Monitor

Note: This procedure is used for the real-time monitoring of VOCs in a liquid stream.

7.2.3.1 The operation of the atomizing, continuous water monitor is thus a liquid pump which draws water from the source to be sampled and forces it at 50 to 100 psi through a small orifice. See Eigure 3 for a schematic diagram of the atomizing, continuous water monitoring module. The Stream of water impacts on the inner wall of the monitor, generating an aerosol. The vocs contained in the water are partitioned from the aerosol into a helium stream which is flowing through the monitor. The sample gas consisting of vocs in the helium stream flows to the mass spectrometer where it is analyzed.

7.2.3.2 Attach continuous monitor probe to ion trap 
7.2.3.3 Check and calibrate direct sampling ion trap mass spectrometer as specified in section 7.1 .

7.2.3.4 Calibration

7.2.3.4.1 Set up data acquisition program. Use either an EI or alternating EI/CI scan function as appropriate for the analytes of interest. Acquistion time should be approximately 30 minutes.

7.2.3.4.2 Insert continuous monitor into a $250 \mathrm{ml}$ beaker of distilled water and start data acquisition.

7.2.3.4.3 After instrument response has stabilized, insert continuous monitor probe into a $250 \mathrm{ml}$ beaker containing the low level standard. Leave monitor probe in place until instrument response is stable. Remove and decontaminate with distilled water.

$7 \cdot 2 \cdot 3 \cdot 4 \cdot 4$

Repeat section 7.2 .2 .7 .3 for as many different levels of calibration desired. Upon completion of calibration, manually stop the data acquistion program and close the data file.

$7.2 \cdot 3.5$

$7 \cdot 2 \cdot 3 \cdot 5 \cdot 1$
Data acquisition (unknowns)

Set up acquisition program. Run time should be at least 20 minutes or longer if needed for a particular application. 
$\begin{array}{ll}\text { 7.2.3.5.2 } & \text { Insert continuous monitor } \\ & \text { probe into a } 250 \mathrm{ml} \text { beaker of } \\ & \text { distilled water to acquire a } \\ & \text { baseline response. Begin data } \\ & \text { acquisition and aliow } \\ & \text { instrument response to } \\ & \text { stabilize. } \\ & \\ & \text { Insert continuous monitor probe } \\ & \text { into the flowing liquid stream. }\end{array}$

$7 \cdot 2 \cdot 3 \cdot 5 \cdot 4$

$7.2 \cdot 3 \cdot 5 \cdot 5$

$7.2 \cdot 3 \cdot 5 \cdot 6$

$7 \cdot 2 \cdot 3 \cdot 5 \cdot 7$
Monitor VoC analyte response until the response as long as needed for a particular application.

Retrieve in continuous monitor probe and rinse with distilled water.

Insert continuous monitor probe into a $250 \mathrm{ml}$ beaker of distilled water. Analyze a blank water sample for baseline response.

After instrument response for the blank has stabilized for at least 1 minute, manually stop the data acquisition program and close the data file.

7.2.3.6 Reduce data as described in section 7.5 .

\subsection{Measurement of vocs in soil}

Note: This procedure is preferred for samples which contain targeted analytes in the range of $1 \mathrm{ug} / \mathrm{kg}$ to $10 \mathrm{ug} / \mathrm{kg}$. Detection limits will be comparable to those for vocs in water provided that the soil matrix does not strongly retain the targeted compounds.

7.3.1 Heated Purge of Soil Slurries (40 ml VOA Vial) 
7.3.1.1 Weigh a $5 \mathrm{~g}$ aliquot of a soil sample on ar. electronic balance to the nearest tenth of a gram

7.3.1.2 Quickly place soil in a $40 \mathrm{ml}$ VOA vial to minimize loss of volatile constituents.

7.3.1.3 Place a stirring bar in the $40 \mathrm{ml}$ vial.

7.3.1.4 Add $40 \mathrm{ml}$ of AEC simulated groundwater to the vial.

7.3.1.5 Add $10 \mu 1$ of internal standard to the water.

7.3.1.6 Quickly attach the $40 \mathrm{ml}$ sample vial to the purge module.

7.3.1.7 Place the aluminum heating sleeve around the $40 \mathrm{~mL}$ VOA vial and support with an appropriate lab jack.

7.3.1.8 Set heater temperature to 140 degrees $F$ and turn on.

7.3.1.9 Place a magnetic stirrer under the $40 \mathrm{ml}$ VOA vial and begin stirring.

7.3.1.10 Follow procedures as outlined in section 7.2.1 for calibration and analysis of unknowns.

Note: See Table 13 for spike recovery comparison data on soil vs water.

7.3.2 Purge of Soil Extracts (40 ml VOA Vial)

Note: This procedure is preferred for samples containing more than $10 \mathrm{mg} / \mathrm{kg}$ of targeted analytes in order to minimize the exposure of the inlets and mass spectrometer to excessive amounts of analyte. Because of the dilution

factors involved, minimum detection limits will generally be in the range of $1 \mathrm{mg} / \mathrm{kg}$.

7.3.2.1 Weigh out a $5 \mathrm{~g}$ aliquot of soil.

7.3.2.2 Quickly place weighed soil in a $40 \mathrm{ml}$ VOA vial to minimize loss of volatile materials.

7.3.2.3 Add $10 \mathrm{ml}$ of methanol to the soil and cap 40 
ml VOA vial with a Teflon-lined(A) screw cap.

7.3.2.4 Extract the vocs from the soil by vigorously shaking the $40 \mathrm{ml}$ VOA vial by hand for 60 seconds.

7.3.2.5 Remove a known aliquot of the extract using a syringe.

7.3.2.6 Inject the methanol extract into a $40 \mathrm{ml} \mathrm{VOA}$ vial containing $40 \mathrm{ml}$ of AEC simulated groundwater.

7.3.2.7 Using a syringe, add exactly $10 \mu l$ of the internal standard to the $40 \mathrm{ml}$ VOA vial containing the methanol extract/water mixture.

7.3.2.8 Attach the $40 \mathrm{mI}$ VOA vial containing the methanol extract/water mixture to the purge module.

7.3.2.9 Follow procedures as outlined in section 7.2.1 for calibration and analysis of unknowns.

7.3.3 Pushing of TDS Probe

7.3.3.1 The location and depth for each TDS push at any particular site are based on previous site knowledge. Factors to be considered include subsuface geology, depth of groundwater, and source of VOC contamination, if known.

7.3.3.2 Advance TDS to predetermined depth. See Figure 4 for a schematic diagram of the TDS probe. Record the depth. Push depths can be automatically tracked on the computer system of the SCAPS cone penetrometer truck. Bring the soil sampling chamber to a temperature of $150^{\circ} \mathrm{C}$ during push to depth.

7.3.4 In Situ Soil Sampling of voC Analytes from Soil

7.3.4.1 Calibrate direct sampling ion trap mass spectrometer as specified in EPA method 8265, Section 7.0.

7.3.4.2 Relieve pressure from probe tip by raising 
probe slightly (this is dependent upon soi? conditions). Direct carrier gas via carriez gas line to the sample. Maintain carrier gas flow at $50 \mathrm{ml} / \mathrm{min}$. Put trap on the TDS

manifold. Retract the interior piston and push 1.8 inches $(4.57 \mathrm{~cm})$ to collect soil sample. Record initial temperature prior to collecting sample and temperature immediately after push to collect sample (this will give an indication of how wet the soil is and will help to determine adjustments to temperature).

7.3.4.3 Attach a vacumn Iine to the end of the trap and pull a vacumn. Record carrier gas flow going down line and back up analyte line. The flow coming up the analyte line should be within approximately $5 \mathrm{ml} / \mathrm{min}$ of that going down.

7.3.4.4 Sample is heated for approximately 5 to 15 minutes depending upon soil moisture and soil type. If sample is initially relatively wet evidenced by a large drop in temperature $\left(>40^{\circ} \mathrm{C}\right)$ then sample time may require 15 minutes to achieve desorption of VOCs from the soil during thermal desorption. Sampling in relatively dry sandy material will be complete in 5 minutes while 15 minutes will be required for clays. The sample chamber is maintained at a temperature between 120$150^{\circ} \mathrm{C}$ depending upon soil moisture conditions.

7.3.4.5 Maintain record of temperatures and carrier gas flows during determined sample interval. Currently the flows can be automatically recorded on the computer system of the SCAPS cone penetrometer truck.

7.3.4.6 After predetermined sample interval, remove trap from manifold, and bring probe up approximately 1 foot, eject soil sample plug, and close the probe. Purge the analyte line while maintaining the chamber temperature at sampling temperature for 10 minutes (this will purge carryover of analytes from the analye line). 
7.3.4.7 Analyze trap for voC analyte response using ion trap mass spectrometry as specified in section 7.0, EPA Method 8265.

7.3.4.7 If detectable concentrations of vocs are found, collect a 5 minute blank sample using the same flow and temperature as in soil sample collection to ensure that the analyte line is clear of any contamination.

7.3.4.8 Several samples can be taken in one push at several depths. After collecting a blank if necessary, push to next predetermined depth and carry out sampling as described above.

7.3.4.9 Retract TDS and push pipe. Decontaminate the TDS and push pipe using a hot water/steam cleaner.

7.4 Measurement of VoCs in Air

\subsubsection{Real-time Air Monitoring}

Note: This procedure is used for real-time direct monitoring of VOCs in air and can be used to detect most targeted analytes at a level of approximately 50 ppbv with a temporal resolution of less than 1 second per data point. For higher sensitivity, the procedure described in section 7.4 .2 (thermal desorption of VoCS collected on sorbent traps) can be used provided that real-time results are not required.

7.4.1.1 Add $20 \mathrm{~L}$ of breathing air to a $20 \mathrm{I}$ Tedlar $\$$ bag using a 2-liter plastic syringe.

7.4.1.2 Using a syringe, add the correct amount of neat compounds to the bag to give a $1000 \mathrm{ppm}$ stock concentration according to the formula below.

$m w *$ barometric press. $(a t m) *$ final conc. desired $(p p m) *$ final vol. $(L)$ liquid density $(\mathrm{g} / \mathrm{mL}) * 82.1(R) *$ temp. $\left({ }^{\circ} \mathrm{K}\right)$

7.4.1.3 Allow the bag containing the neat compounds to 
set still until they evaporate.

7.4.1.4 Then, using both hands, pat or squeeze the bag gently in various places on the bag to create a homogeneous mixture of the compounds. Do this for approximately $1.5 \mathrm{~min}$.

7.4.1.5 Fill five $10 \mathrm{I}$ Tedlar@ bags with $10 \mathrm{~L}$ of breathing air to generate a 5-point calibration curve. See Table 11 for preparation of these calibration standards in air.

7.4.1.6 Using the correct size syringe, draw out the correct amount of gas from the stock concentration bag and quickly inject it into the $10 \mathrm{~L}$ Tedlar bag.

7.4.1.7 Mix the VOCs in the bag according to section 7.4.1.4 to obtain homogeneity.

7.4.1.8 To prepare a blank sample, fill a Tedlar® bag with the same breathing air that was used in the standards.

7.4.1.9 Set up Data Acquisition to acquire three replicate analyses of each concentration for the entire calibration run.

7.4.1.10 Name the data acquisition file by whatever name is convenient and type in comments under "comment" section (optional).

7.4.1.11 Attach the air monitoring module to the ITMS and adjust the air flow to approximately 100 $\mathrm{ml} / \mathrm{min}$. See Figure 5 for a schematic diagram of the monitor.

7.4.1.12 Attach the blank bag sample to the air monitor and loosen screw on bag inlet valve enough to push the valve to the "in" position to start sampling. Then tighten the screw to hold the valve in place. Acquire data on blank for 2 minutes.

7.4.1.13 Loosen the valve screw on the blank bag enough to pull the valve to the "out" position to stop the sampling. Then tighten screw again to 
hold the valve in the "out" position to avoid loss of sample.

7.4.1.14 Remove the blank sample and replace it with a calibration standard, starting with the lowest concentration and acquire for 2 minutes.

7.4.1.15 Remove calibration standard and replace with the blank and acquire for 2 minutes.

7.4.1.16 Repeat sections 7.4.1.12-7.4.1.15 two more times for a total of three replicate for each calibration point.

Note: Some VoCs may require more than a 2minute run before reaching it's maximum response , particularly at higher concentrations.

7.4.1.17 Reduce data as described in section 7.5 .

7.4.2 Thermal Desorption of VOCs Collected on Sorbent Traps

Note: This procedure is used for the measurement of VOCs which have been collected and preconcentrated on a sorbent material.

7.4.2.1 Load the sorbent cartridge containing the vocs into the thermal desorber at ambient temperature. After the desorber has been resealed with the septum cap, allow it to set for 20 seconds while all the oxygen is purged from the interior by a stream of helium flowing at $15 \mathrm{ml} / \mathrm{min}$. The desorber is then flash-heated (less than 30 seconds) to $200^{\circ} \mathrm{C}$. The voCs are carried from the sorbent cartridge into the mass spectrometer by the helium stream.

7.4.3.2 Generate a calibration curve by loading sorbent cartridges with known amounts of the analytes of interest in the gas phase into a stream of inert gas flowing 100 to $200 \mathrm{ml} / \mathrm{min}$. through a tee, followed by thermal desorption of these loadings. See Figure 6 for a schematic diagram of the thermal desorber. 
7.5.1 VoCs in water

7.5.1.1 Deconvolute the combined EI/CI data into separate EI and CI data files using the ITMS program UNSCRAM (or equivalent) for any of the raw data files resulting from a sparging experiment described in Section 7 .

7.5.1.2 For data reduction in the EI mode, retrieve a sample spectrum from a given "unscrambled" data file using $\langle F\rangle$ 
(Eile Manager Program), and store it on the PLOT SPOOLER (see Table 8 for a typical EI spectrum and purge profile).

7.5.1.3 Integrate the data in the manual mode using 45 scans/integration, only if there is an EI response for the characteristic ions of the analyte of interest greater than the background (refer to Table 5).

7.5.1.4 Save all integrated data on the PLOT SPOOLER (see Table 8 for a typical CI spectrum and purge profile).

7.5.1.5 For data reduction in the CI mode, retrieve a sample spectrum from a given "unscrambled" data file using <El> (File Manager Program), and store it on the PLOT SPOOLER.

7.5.1.6 Integrate data in the manual mode using 45 scans/integration, only if there is a CI response greater than the background for characteristic ions of interest. Refer to Table 5 for list of ions.

7.5.1.7 Save all integrated data on PLOT SPOOLER.

7.5.1.8 Calculation of Detection Limits/Unknown Concentration

7.5.1.9 Prepare a data spreadsheet using a program such as Lotus 1-2-3® showing the measured integrated areas of the analyte vs. concentration. Please be advised that other data processing systems with similar capabilities can be used as well.

7.5.2.0 Use the linear regression feature of the spreadsheet program to calculate the relationship between concentration and the measured integrated areas of the analytes.

7.5.2.1 Calculate MDL and CRL values from the procedure in Table 6 (See Table 5 for MDL[s] and CRI[s] for the 34 target compounds calculated using this method.) 
7.5.3 voCs in Air

7.5.3.1 Retrieve and reduce the data files in the same manner as described in section 7.5 .

Integrate a one-minute scan of each calibration point, including the blanks to obtain the peak area, and then save to the Plot Spooler by clicking on "Alt S". See Table 12 for the list of ions of interest.

7.5.3.2 Calculate MDL[s] according to section 7.5.2.1. Refer to Table 12 for 32 of the 34 target compounds calculated using this method.

7.5.4 VOCs in Soil

7.5.4.1 Retrieve, reduce, and integrate the data in the same manner as described in section 7.5 .

7.5.5 Quantitation

7.5.5.1 Calculate concentration of analytes in unknown water, air, and soil samples using the linear regression model $\mathrm{y}=\mathrm{mx}+\mathrm{b}$ with a non-zero intercept.

8.0 QUALITY CONTROL

8.1 Refer to Chapter One and Method 8000 for specific quality control procedures.

8.2 The percent recovery for QC sample should fall within the limits listed in Table 7 found in 40 CFR Part 36 for Method 624. The percent recoveries for the target volatile organic compounds obtained by this method is found in Table 9. This criterion is not applicable to compounds not found on this list.

\subsection{METHOD PERFORMANCE}

9.1 Tables 7 and 9 present performance data generated for Method 8265 . 


\subsection{REFERENCES}

1. Einnigan MAT Ion Trap Detector Operation Manual, Revision G, January, 1989, San Jose, California.

2. Test Methods for Evaluating Solid Waste, Volume IB: Laboratory Manual Physical Chemical Methods, SW-846, November, 1986.

3. Rocky Mountain Arsenal Chemical Quality Assurance Plan, Version 1.0, July 1989, pp.4-7.

4. 40 CFR Part 36 for Method 624 .

5. Code of Federal Regulations, 1990 "Definition and Procedure for the Determination of the Method Detection Limit", Code of Eederal Regulations, Part 136, Appendix B, pp. 537.

6. USATHAMA, 1990, U.S. Amy toxic and Hazardous Materiais Agency: Quality Assurance Program, Aberdeen Proving Ground, MD.

7. Grant, C.L., Hewitt, A.D., and Jenkins, T.F. (1991) American Laboratory $23,15-33$.

8. Hubaux, A., and Vos, G. (1970) Analytical Chemistry 42, 849855 .

9. Wise, M.B.; Thompson, C.V.; Buchanan, M.V.; Merriweather, R.; Guerin, M.R. Spectroscopy, 1993, 2(5), 14-22. 


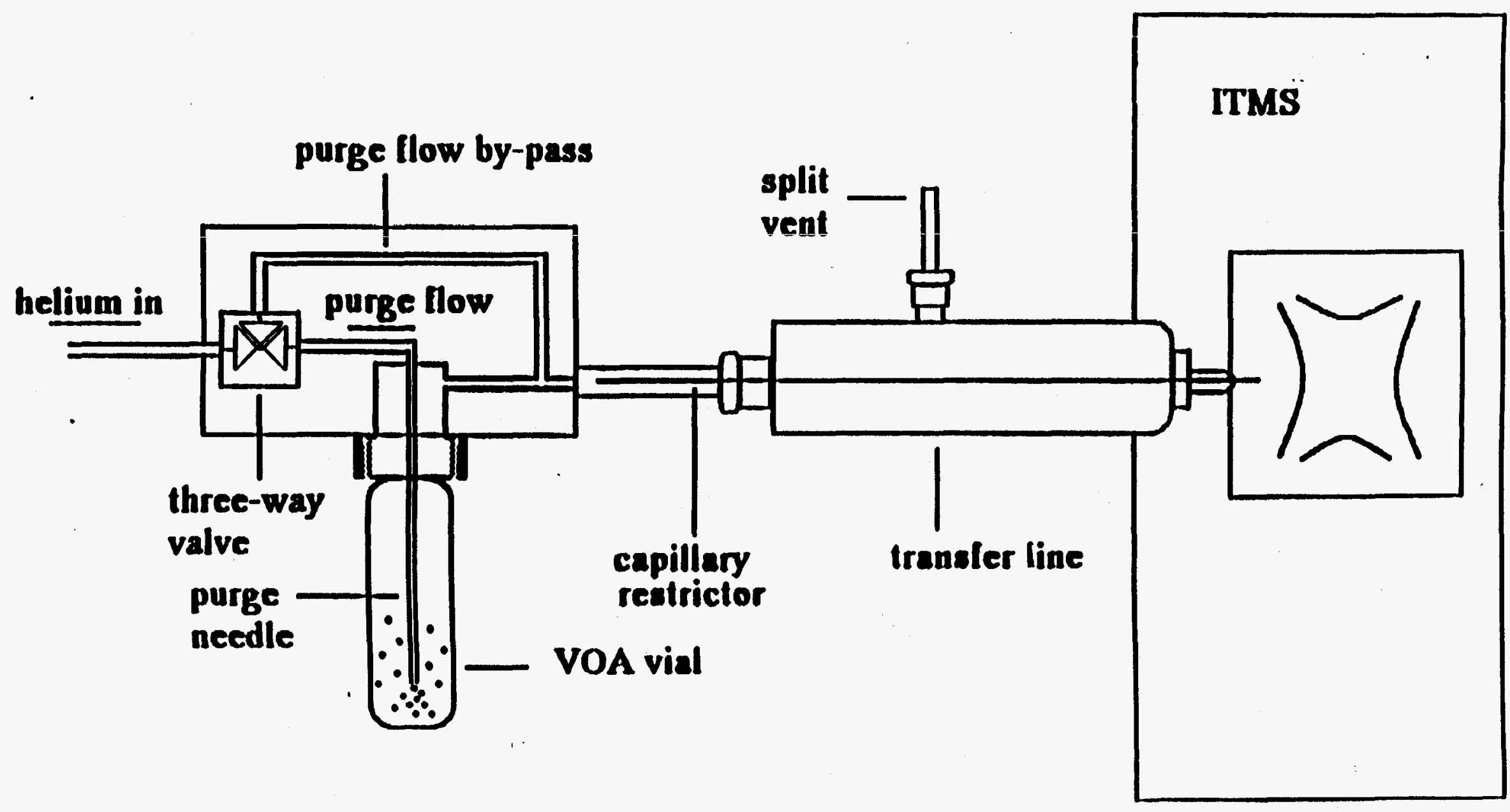

Figure 1: Purge Device for the Analysis of VOCs in $40 \mathrm{ml}$ Water Vials 
Figure 2

\section{In Situ Water Monitoring System}

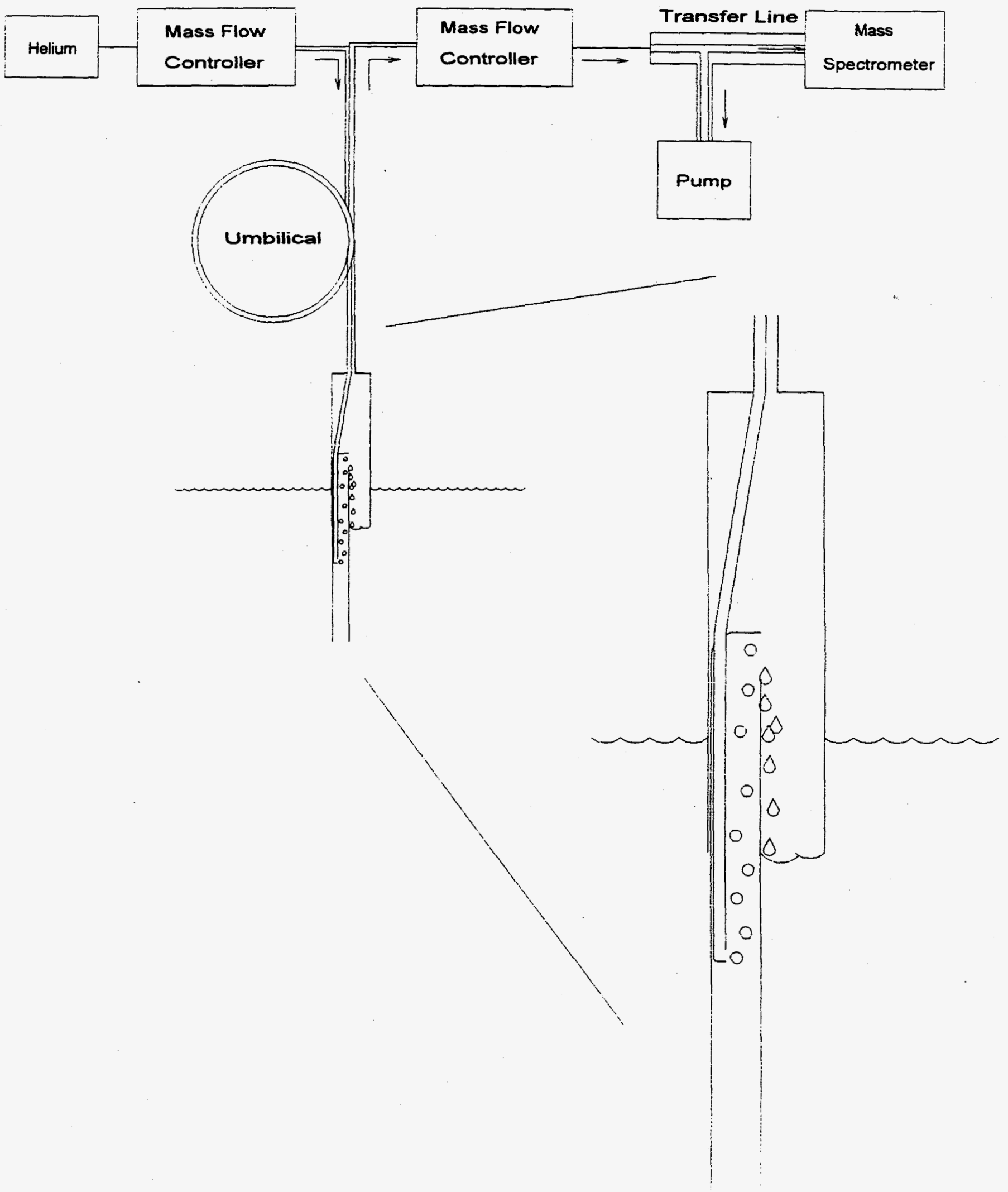




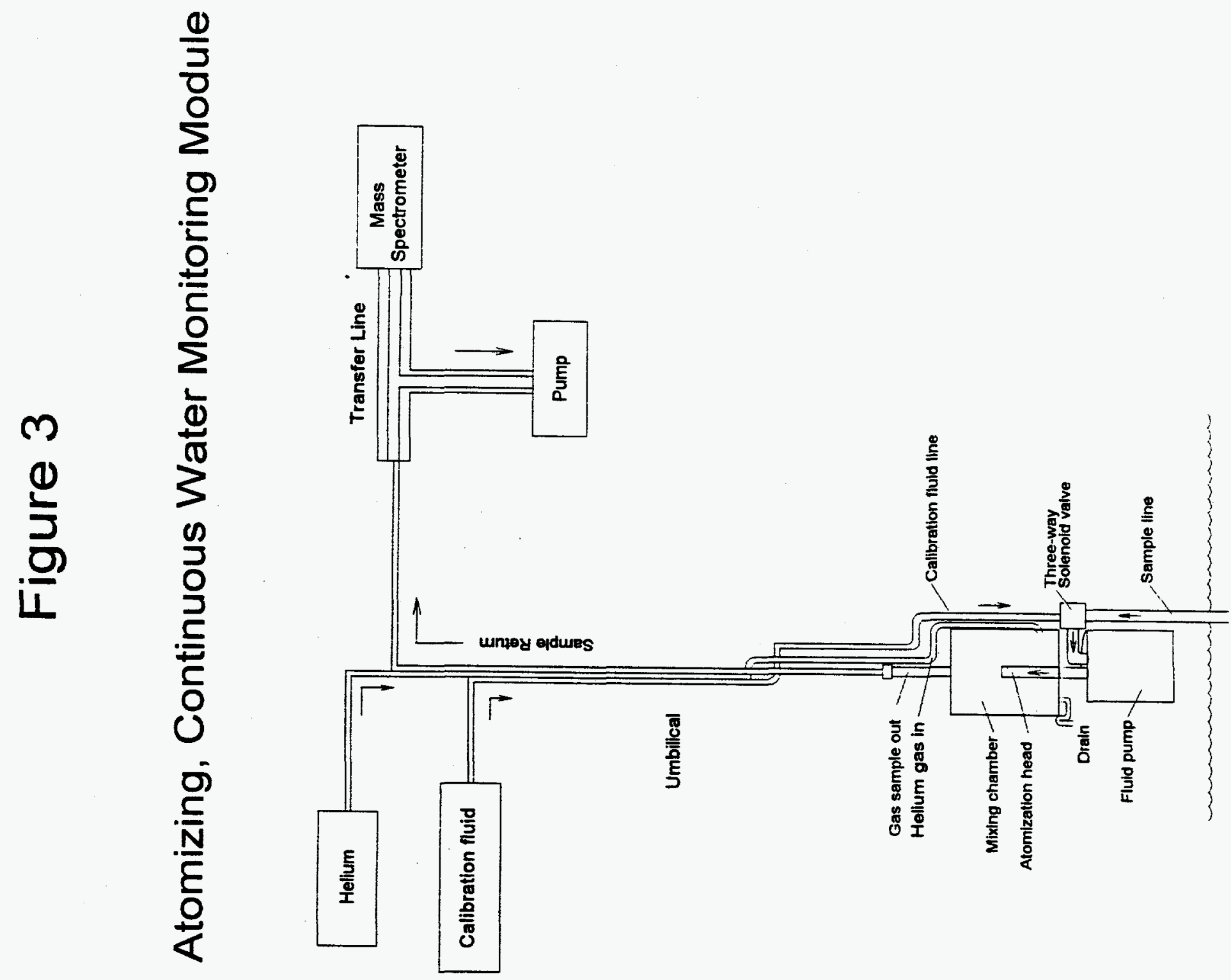




\section{Figure 4}

\section{Thermal Desorption Push Probe}

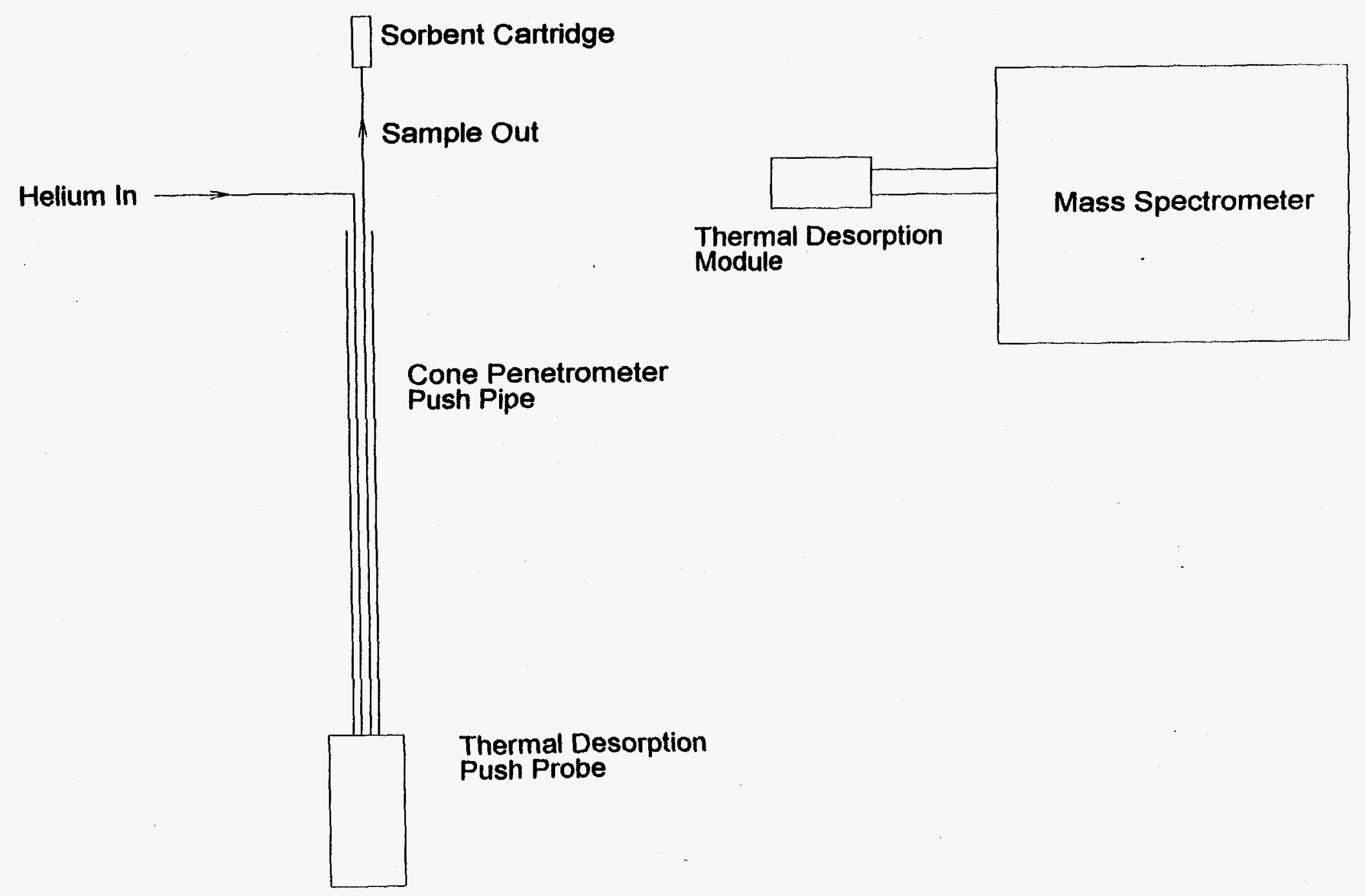




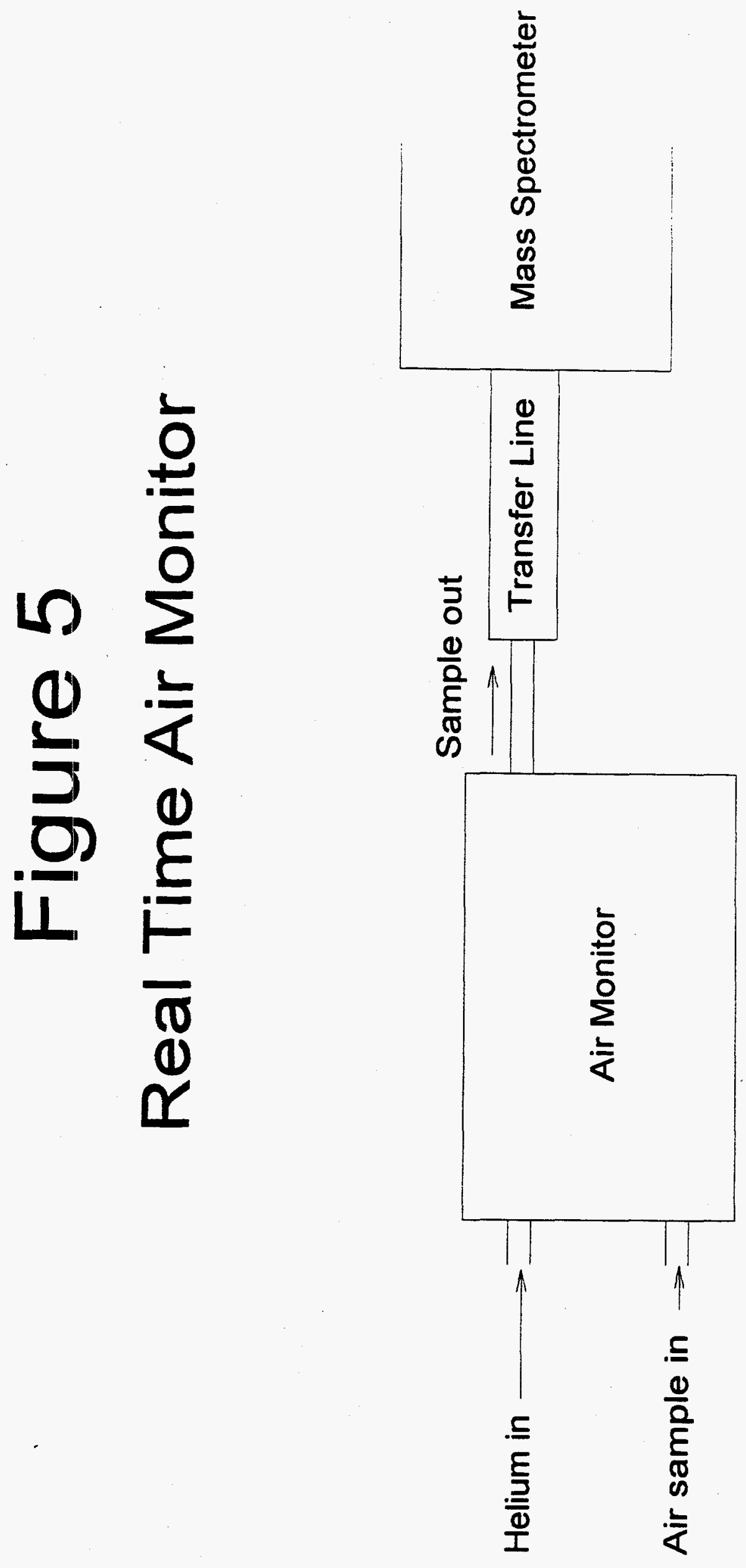




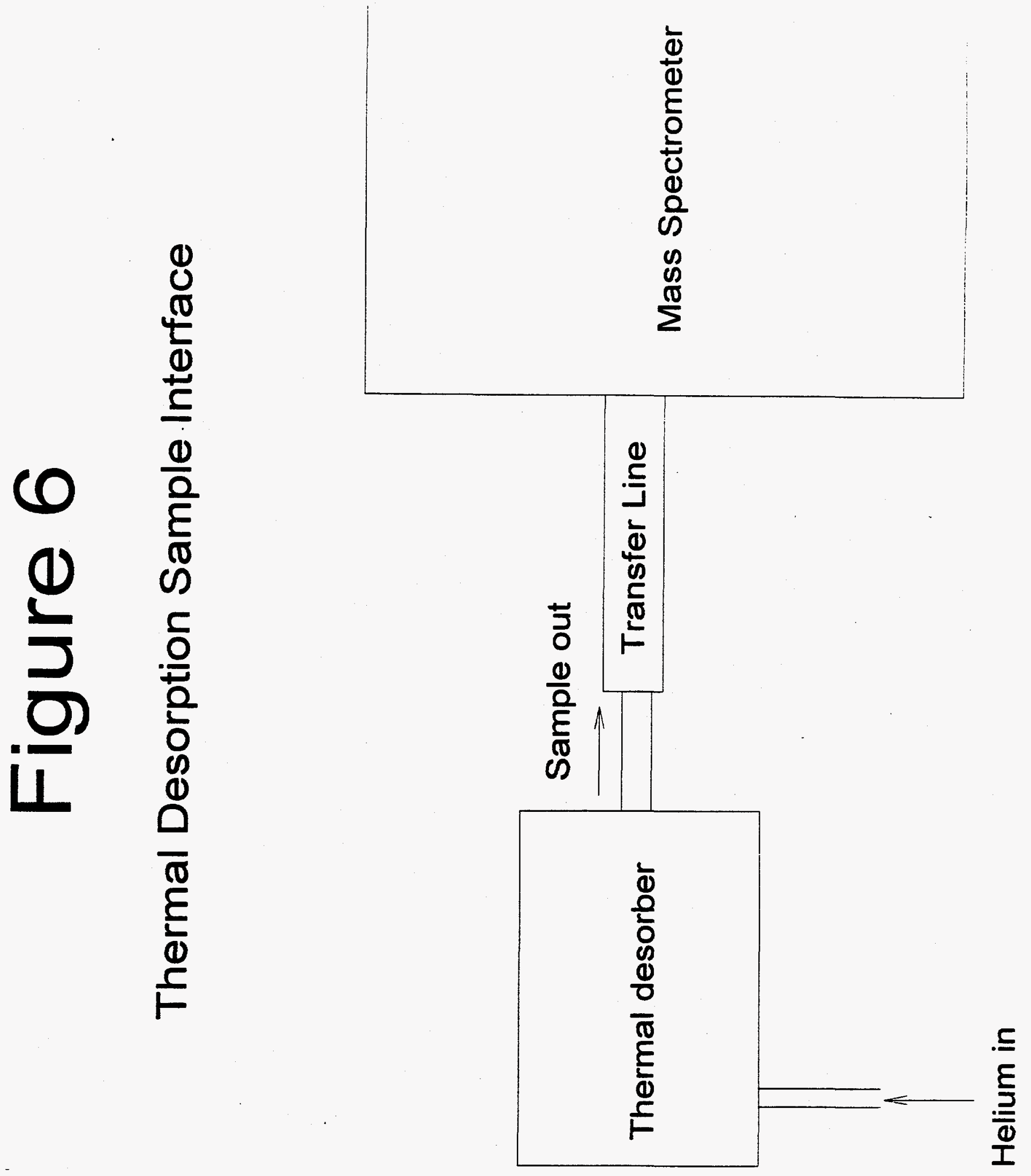


Table 1

DETAILS OF THE SCAN FUNCTION "DSF" USED IN THE ITMS PROTOCOL

SCAN FUNCTION $=>C: D S E . S E D$

COMMENT $\Rightarrow$ one segment BTT EI scan

SAMPLE PRESSURE

BASE PRESSURE

Title

$\begin{array}{cccccccc}\text { Star } & \text { End } & \text { DC } & \text { ISO } & \text { TICK } & \text { TIC } & \text { FREQ- } & \text { Time } \\ t & \text { lamu } & \text { (V) } & \text { lamu } & \text { lamu } & \text { K } & \text { DELT } & \text { (msec) } \\ \text { lamu } & 1 & & 1 & 1 & \text { (mV } & \text { (Hz) } & \\ 1 & & & & & 1 & & \end{array}$

$0.0 \quad 0.0$

$41.0 \quad 41.0$

$41.0 \quad 41.0$

$41.0 \quad 41.0$

41.0250.

$0.0 \quad 0$

$0.0 \quad 0.0$

$14.0 \quad 0.0$

$14.0 \quad 14.0$

$14.0 \quad 14.0$

$14.0 \quad 14.0$

$14.0 \quad 14.0$

$14.0 \quad 14.0$

$60.0 \quad 60.0$

$30.0 \quad 30.0$

$30.0 \quad 30.0$

0.0200 .

0.0

24. 16.3

$\begin{array}{lll}41.1 & 500 & 0 \\ 41.1 & 0 & 0 \\ & 500 \\ & 0\end{array}$

0.10

5.00

1.00

1.00

38.34

Acq]

0.60

0.05

0.20

5.00

0.20

0.20

75.00

1.50

30.1

1.00

30.1

0
0

1.00

0.60

1.00
[ $\mathrm{Tr}_{r}$ ]

[ Fil.]

[ Tic., Mult,] I Tic., Mult,
600

0 


\section{DETAILS OF THE "FORTH" PROGRAM "TTVBTX" USED IN THE ITMS PROTOCOL}

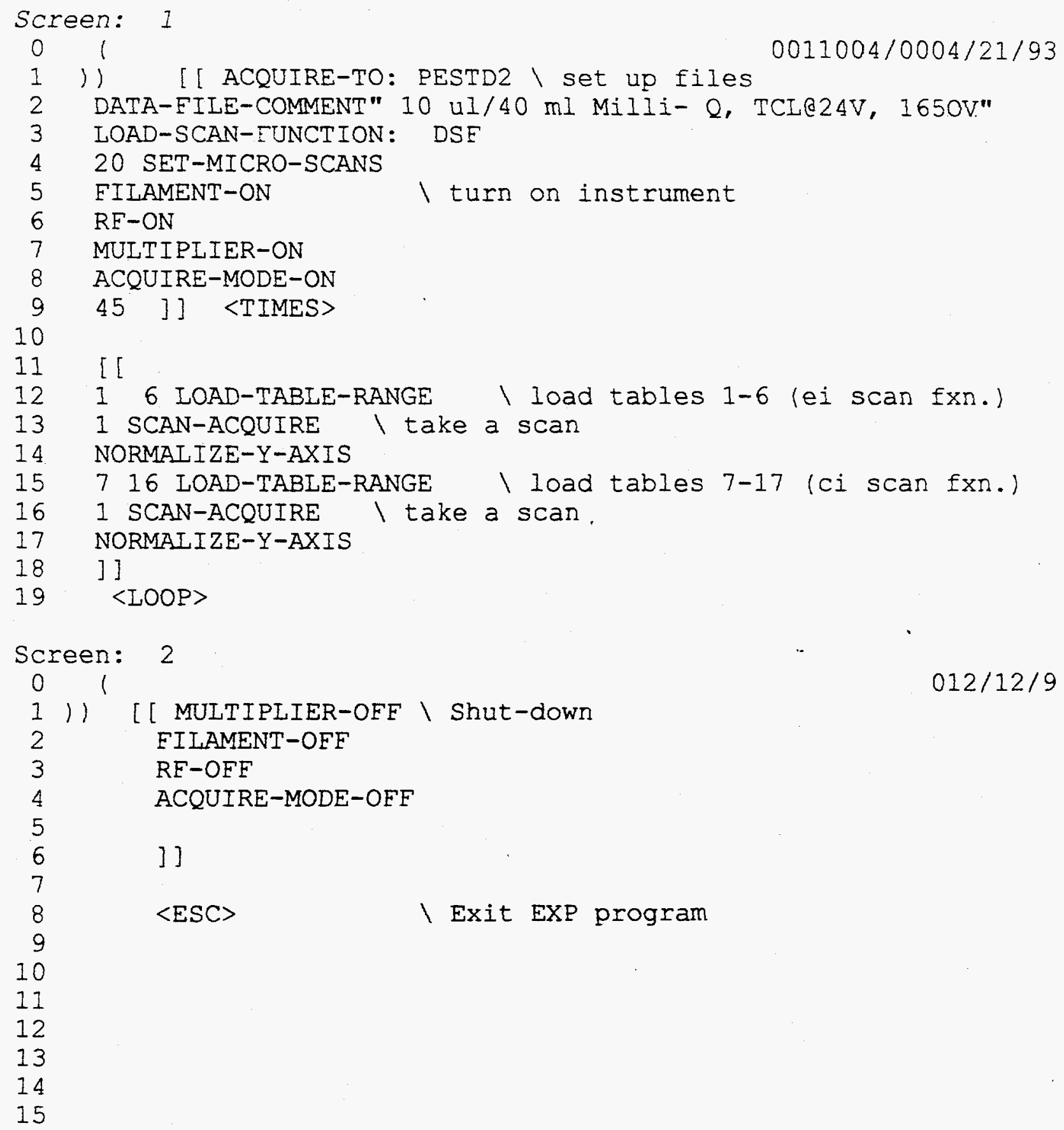


Table 3

VOLUMES OF NEAT LIQUID REQUIRED TO PREPARE "MASTER" STOCK SOLUTIONS \& $5000 \mu \mathrm{g} / \mathrm{mL}$ IN $10 \mathrm{ML}$ VOLOME OF THE TARGET VOIATILE COMPOUNDS SPECIEIED BY TEE U.S. ENVIRONMENTAL PROTECTION ANGENCY

\section{Compound Name}

Acetone

Methyl Isobutyl Ketone

Methyi Ethyl Ketone

2-Hexanone

Total Xylenes

Toluene

Ethyl Benzene

Benzene

Styrene

Vinyl Acetate

Chlorobenzene

1,2-Dichloropropane

1,1-Dichloroethane

1,1-Dichloroethene

trans-1,3-

Dichloropropene

cis-1, 3-

Dichloropropene

1,2-Dichloroethane

Carbon Disulfide

1,2-Dichloroethene

(total)

Dichloromethane

$1,1,1-$

Trichloroethane

$1,1,2-$

Trichloroethane

Trichloroethylene

Chloroform

$1,1,2,2-$

tetrachloroethane
Density

$\mathrm{mg} / \mathrm{mI}$

0.7880

0.8010

0.8050

0.8120

0.8600

0.8623

0.8660

0.8737

0.9059

0.9320

1.1004

1.1590

1.1680

1.2129

1.2200

1.2200

1.2569

1.2632

1.2650

1.3170

1.3376

1.4416

1.4640

1.4798

1.5866

$8265-38$
III

Req'd

63.4

62.4

62.1

61.6

58.1

57.1

57.7

57.2

55.2

53.7

45.4

43.1

42.8

41.2

41.0

43.0

39.8

39.6

39.5

38.0

37.4

34.7

34.2

33.8

31.5
Revision WG

Nov. 1996 
Carbon Tetrachloride

Tetrachloroethylene

Bromodichloromethane

Dibromochloromethane

Bromoform
1.5890

1.6230

1.9800

2.4330

2.9035
31.5

30.8

25.2

20.6

17.2 
ANALYTE CONCENTRATION VS VOLUME OF WORRTNG STOCK SOLUTIONS USED

\section{Desired Analyte Concentration} $\mathrm{ng} / \mathrm{mI}$

0
2
5
15
25
50

0

2

5

15

25

50
Volume of Working stock Solution (pI)

Required for $40 \mathrm{~mL}$ Water

$\begin{array}{cc}0 & 0 \\ 2 & 0.8 \\ 5 & 2 \\ 5 & 6 \\ 0 & 10 \\ \end{array}$


Table 5

\section{IIST OE THIRTY-FOUR EPA TARGET COMPOUNDS, DETECTION IIMITS, AND CHARACTERISTICS IONS}

Detection limits estimated from a calibration line over the target concentration range of 0 to $15 \mathrm{ppb}$.

\begin{tabular}{|c|c|c|c|c|c|c|}
\hline \multirow[b]{2}{*}{ Compound } & \multicolumn{3}{|c|}{ Electron Impact } & \multicolumn{3}{|c|}{ Chemical Ionization } \\
\hline & $\begin{array}{l}\text { Peak } \\
\text { (mz) }\end{array}$ & $\begin{array}{c}M D L \\
\text { (ppb) }\end{array}$ & $\begin{array}{c}\text { CRL } \\
\text { (ppb) }\end{array}$ & $\begin{array}{l}\text { Peak } \\
\{\mathrm{mz}\}\end{array}$ & $\begin{array}{c}M D L \\
\{p p b\}\end{array}$ & $\begin{array}{c}\text { CRL } \\
\text { (ppb) }\end{array}$ \\
\hline Acetone & & & & 59 & 2.3 & 3.1 \\
\hline Benzene & 78 & 1.3 & 1.7 & 79 & 1.7 & 2.3 \\
\hline Bromodichloromethane & 83 & 2.5 & 3.3 & & & \\
\hline Bromoform & 173 & $2.0 *$ & $2.7 *$ & & & \\
\hline Bromomethane & 94 & 2.4 & 3.2 & & & \\
\hline Carbon Disulfide & 76 & 1.5 & 2.1 & & & \\
\hline Carbon Tetrachloride & 117 & 1.3 & 1.8 & & & \\
\hline Chlorobenzene & 112 & $0.5^{\star}$ & $0.6^{*}$ & 113 & $1.4^{*}$ & $1.8 *$ \\
\hline Chloroethane & 49 & 3.2 & 4.2 & & & \\
\hline Chloroform & 83 & 1.5 & 2.0 & & & \\
\hline Chioromethane & 49 & 4.7 & 6.3 & & & \\
\hline Dibromochloromethane & 129 & 4.4 & 5.8 & & & \\
\hline 1,1-Dichloroethane & 63 & 3.0 & 4.0 & & & \\
\hline 1.2-Dichloroethane & 62 & 1.5 & 1.9 & & & \\
\hline 1,1-Dichloroethene & 96 & 2.0 & 2.6 & 97 & 2.6 & 3.5 \\
\hline $\begin{array}{l}\text { cis }-1,2- \\
\text { Dichloroethylene }\end{array}$ & 96 & 2.5 & 3.3 & & & \\
\hline $\begin{array}{l}\text { trans }-1,2- \\
\text { Dichloroethylene }\end{array}$ & 96 & 1.7 & 2.3 & & & \\
\hline Dichloromethane & 49 & 3.0 & 4.0 & & & \\
\hline 1,2-Dichloropropane & 76 & 3.2 & 4.2 & & & \\
\hline Cis-1,3-Dichloropropene & 75 & 2.2 & 2.9 & 75 & 2.0 & 2.7 \\
\hline $\begin{array}{l}\text { trans }-1,3- \\
\text { Dichloropropene }\end{array}$ & 75 & 1.9 & 2.5 & 75 & 1.5 & 2.0 \\
\hline Ethyl Benzene & 91 & 1.3 & 1.7 & 107 & 1.4 & 1.8 \\
\hline 2-Hexanone & & & & 101 & 2.1 & 2.8 \\
\hline Methyl Ethyl Ketone & & & & 73 & 3.2 & 4.2 \\
\hline Methyl Isobutyl Ketone & & & & 101 & 2.6 & 3.4 \\
\hline styrene & 104 & 0.5 & 0.7 & 205 & 0.9 & 1.2 \\
\hline $\begin{array}{l}1,1,2,2- \\
\text { Tetrachloroethane }\end{array}$ & 97 & 2.1 & 2.8 & & & \\
\hline Tetrachloroethylene & 166 & 1.3 & 1.7 & & & \\
\hline
\end{tabular}




\begin{tabular}{|c|c|c|c|c|c|c|}
\hline \multirow[b]{2}{*}{ Compound } & \multicolumn{3}{|c|}{ Electron Impact } & \multicolumn{3}{|c|}{ Chemical Ionization } \\
\hline & $\begin{array}{l}\text { Peak } \\
(\mathrm{mz}) \\
\end{array}$ & $\begin{array}{c}\mathrm{MDL} \\
(\mathrm{ppb})\end{array}$ & $\begin{array}{c}\mathrm{CRL} \\
\text { (ppb) }\end{array}$ & $\begin{array}{l}\text { Peak } \\
\text { (mz) }\end{array}$ & $\begin{array}{c}\mathrm{MDL} \\
\text { (ppb) }\end{array}$ & $\begin{array}{c}\text { CRL } \\
\text { (ppb) }\end{array}$ \\
\hline Toluene & 91 & 0.5 & 0.6 & 93 & 0.5 & 0.6 \\
\hline $1,1,1$-Trichloroethane & 97 & 0.6 & 0.8 & & & \\
\hline 1,1,2-Trichloroethane & 96 & 3.3 & 4.3 & & & \\
\hline Trichloroethylene: & 132 & 2.7 & 3.5 & & & \\
\hline Vinyl Acetate & & & & 75 & 3.3 & 4.4 \\
\hline Vinyl Chloride & 62 & 1.0 & 1.3 & & & \\
\hline Xylenes & 91 & 0.8 & 1.1 & 107 & 1.9 & 2.5 \\
\hline
\end{tabular}

- One deviate data point omitted from calculations.

Blanks in the table indicate that the method was not used. 
Table 6

DETECTION LIMITS CALCULATION PROCFDURE

Estimate the MDL over the Target Concentration Range of 0-15 ppb:

(1) Calculate and plot the regression line representing the relationship between the "instrument response" vs. "target concentration" with appropriate one-sided upper 99\% confidence limits for a predicted observation.

(2) Locate the intercept of the upper $99 \%$ predictive confidence limits with the y-axis ("instrument response").

(3) Draw a horizontal line from the intercept described in (2) until it intersects the regression line.

(4) Draw a vertical line from the intercept described in (3) to the $x$-axis ("target concentrations"). This intersection with the $x$-axis is the MDL.

Estimate the CRI over the Target Concentration Range of $0-15$ ppb:

(1) Calculate and plot the regression line representing the relationship between the "instrument response" vs. "target concentrations" with appropriate two-sided $90 \%$ confidence limits for a predicted observation.

(2) Locate the intercept of the upper $90 \%$ predictive confidence limits with the $\mathrm{y}$-axis ("instrument response").

(3) Draw a horizontal line from the intercept described in (2) until it intersects the lower $90 \%$ predictive confidence limits.

(4) Draw a vertical line from the intercept described in (3) to the $x$-axis ("target concentrations"). This intersection with the $x$-axis is the CRL. 
Table 6 (Cont'd)

DETECTION IIMITS CALCULATION PROCHDURE

Response

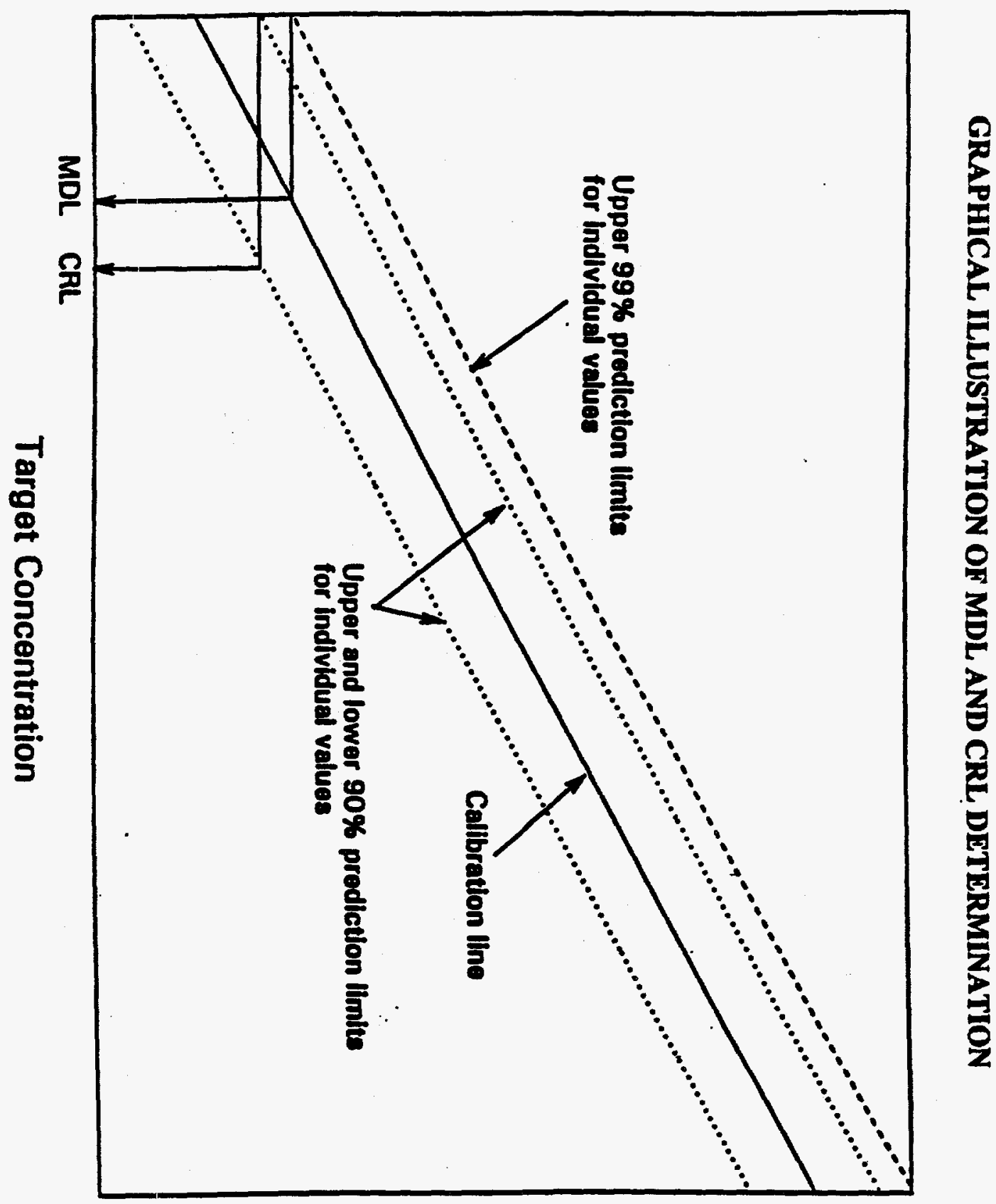


Table 7

\section{EPA QC ACCEPTANCE CRITERIA}

\section{Compound}

Benzene

Bromodichloromethane

Bromoform

Bromomethane

Carbon Tetrachloride

Chlorobenzene

Chloroform

Chloromethane

Dibromoch loromethane

1, 1-Dichloroethane

1, 2-Dichloroethane

1, 1-Dichloroethene

trans $-1,2-$

Dichloroethene

1, 2-Dichloropropane

cis-1, 3-

Dichloropropene

trans-1, 3-

Dichloropropene

Ethyl benzene

Methylene chloride

$1,1,2,2-$

Tetrachloroethane

Tetrachloroethene

\section{\& Recovery}

Range

$37-151$

35-155

45-169

D-242

$70-140$

$37-160$

51-138

D-273

53-149

59-155

49-155

D-234

$54-156$

D-210

D-227

$17-183$

$37-162$

D-221

46-157

$64-148$ 


$$
\begin{array}{lc}
\text { Toluene } & 47-150 \\
1,1,1-T r i c h l o r o e t h a n e & 52-162 \\
1,1,2-T r i c h l o r o e t h a n e & 52-150 \\
\text { Trichloroethene } & 71-157 \\
\text { Vinyl Chloride } & D-251
\end{array}
$$

$D=$ Detected; results must be greater than zero.

Criteria from 40 CFR Part 136 for Method 624 and were calculated assuming a QC check sample concentration of $20 \mathrm{ug} / \mathrm{L}$. 
Table 8

Spectrum and Purge Profile of Chlorinated Hydrocarbons in Water in EI Mode

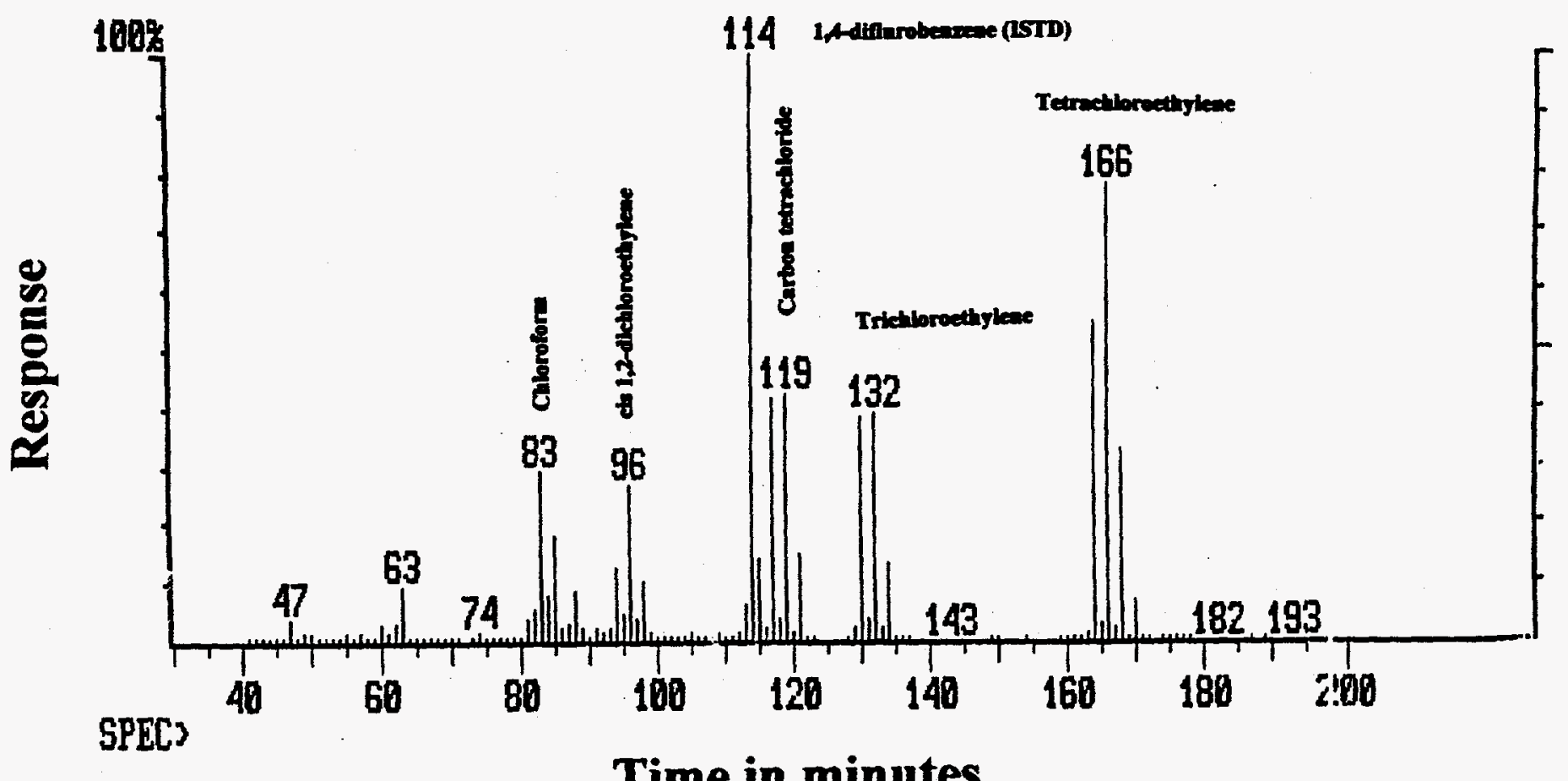

\section{Water Purge Profile}

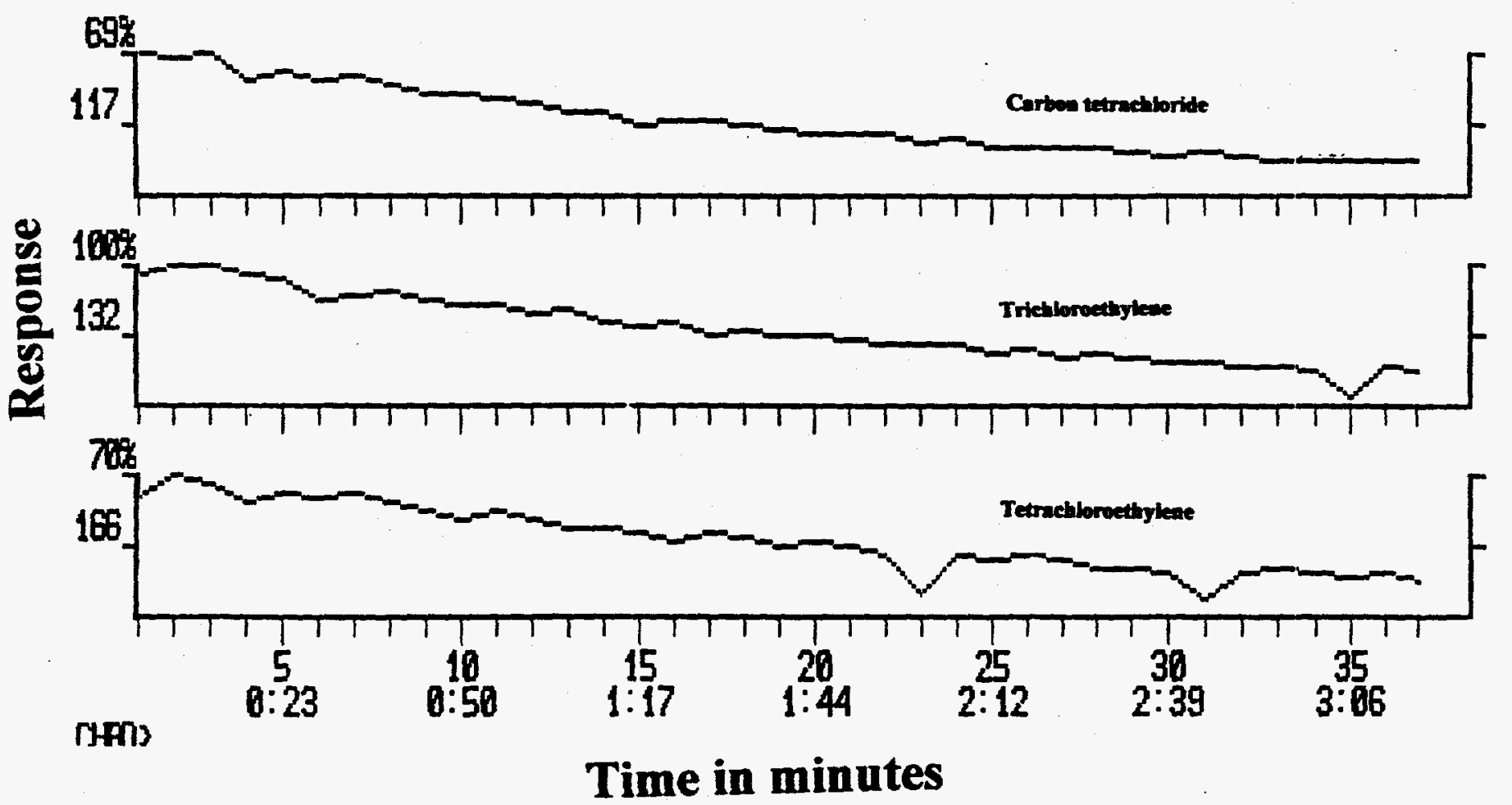


Table 8 (Cont'd)

Spectrum and Purge Profile of Acetone and Aromatic Hydrocarbons in Water in CI Mode

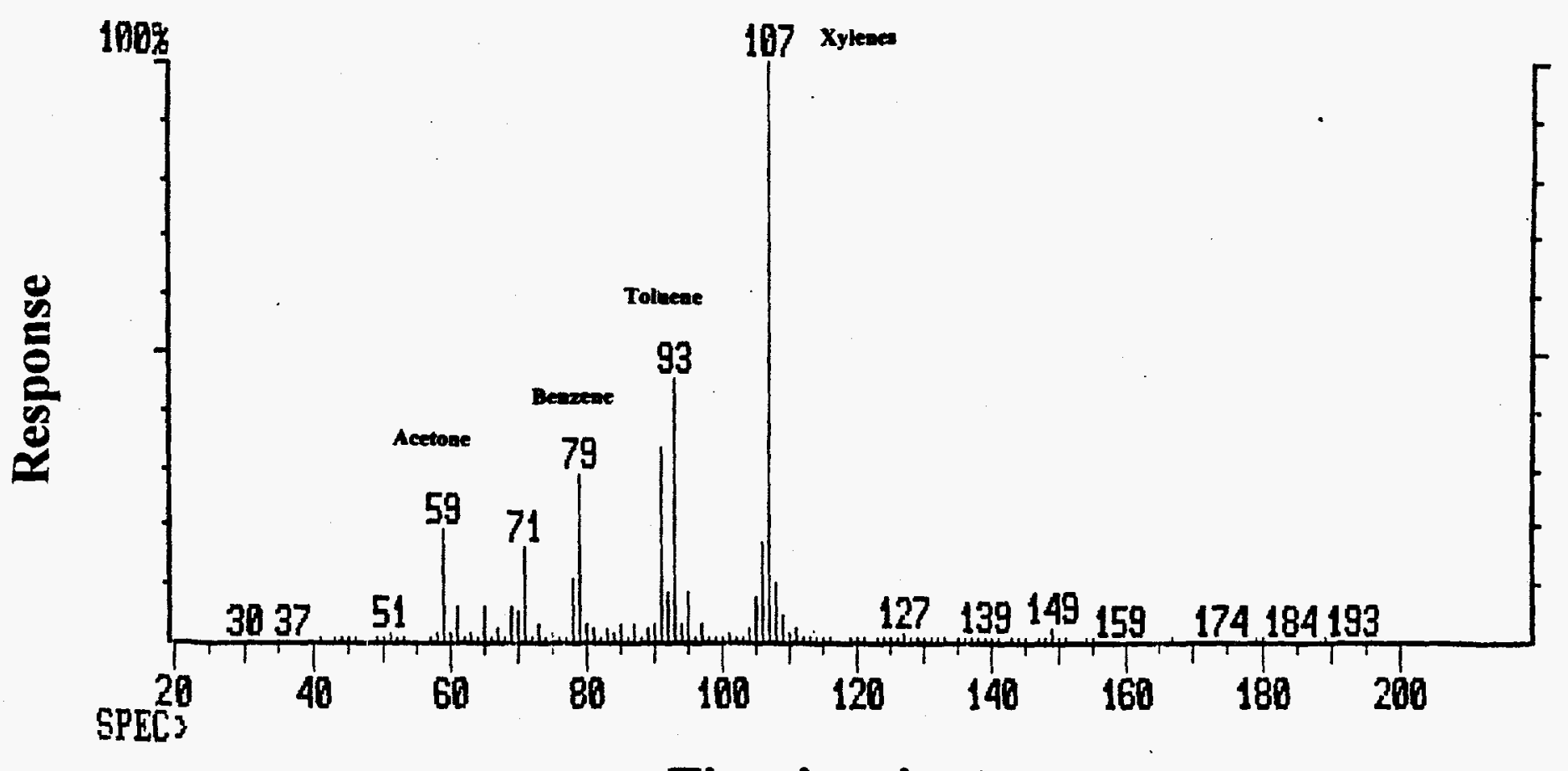

Time in minutes

\section{Water Purge Profile}

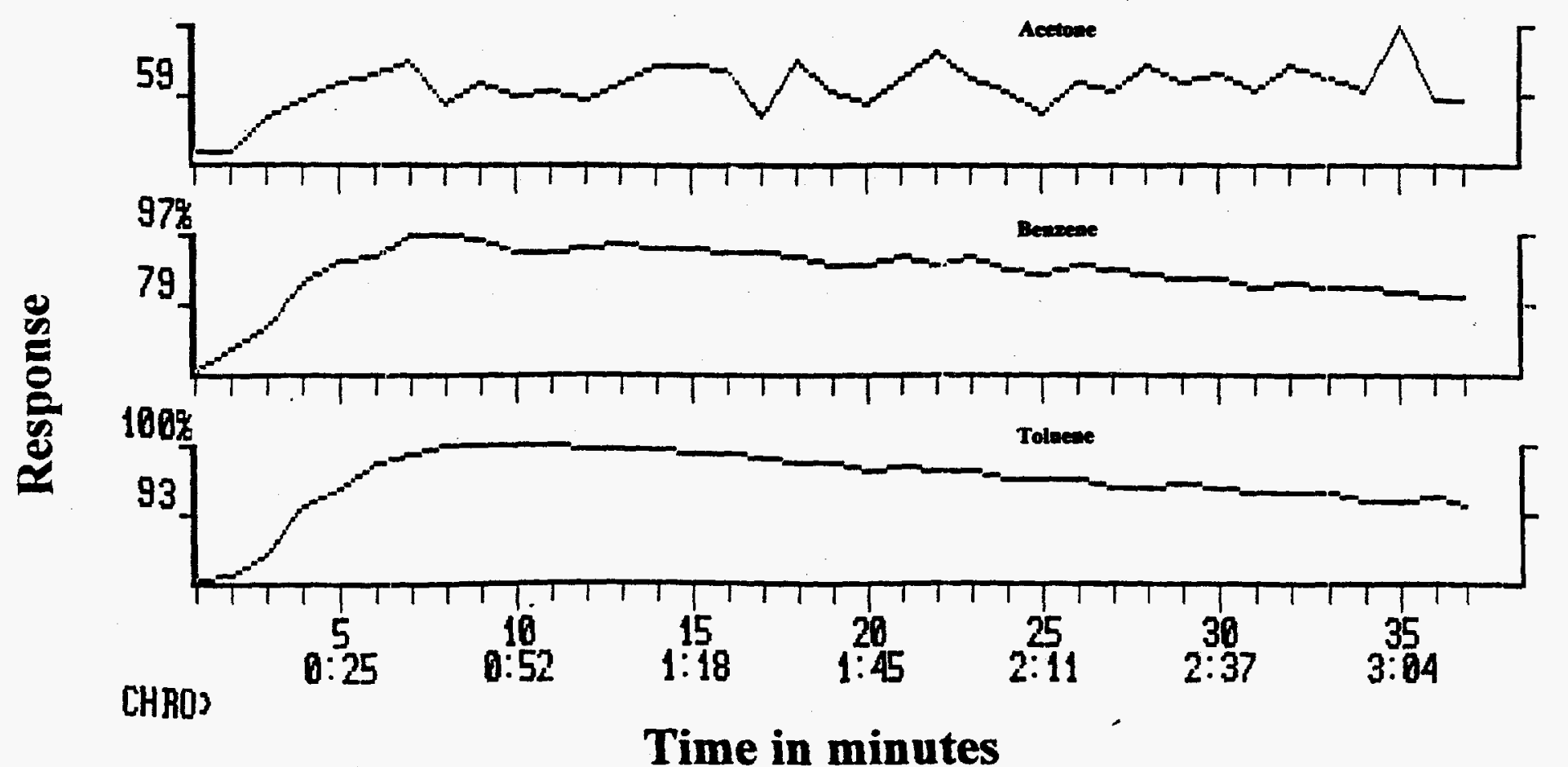


Table 9

\section{QC SAMPLE RECOVERY RESULTS}

\section{VOC}

Acetone
Benzene
Bromodichloromethane
Bromoform
Bromomethane
Carbon Tetrachloride
Chlorobenzene
Chloroethane
Chloroform
Chloromethane

Dibromochloromethane

I, 1-Dichloroethane

1, 2-Dichloroethane

1. 1-Dichloroethene

cis-1, 2-Dichloroethylene

trans-1, 2-Dichloroethylene

Dichloromethane

1, 2-Dichloropropane

1, 1, 2, 2-tetrachlorethane

cis 1, 3-Dichloropropene

trans-1, 3-Dichloropropene

Ethyl Benzene

2-Hexanone

Methyl Ethyl Ketone

Methyl Isobutyl Ketone

styrene

Tetrachloroethylene

Toluene

1. 1, 1-Trichloroethane

1. 1, 2-Trichloroethane

Trichloroethylene

Vinyl Acetate

Vinyl Chloride

\section{\& Recovery Range}

94

107

96.5

123

74.7

100

107

139

104

158

112

96.5

96

103

107

112

118

122

93

106

111

104

104

109

107

109

97

103

118

104

103

107

147 
voc

Total Xylenes

\section{\& Recovery Range}

90.7
Revision WG

Nov. 1996 
Table 10

TYPICAI CAIIBRATION CURVES OF A KETONE, AROMATIC EYDROCARBON AND A HALOCARBON IN THE ELECTRON AND CHEMICAI IONIZATION MODE
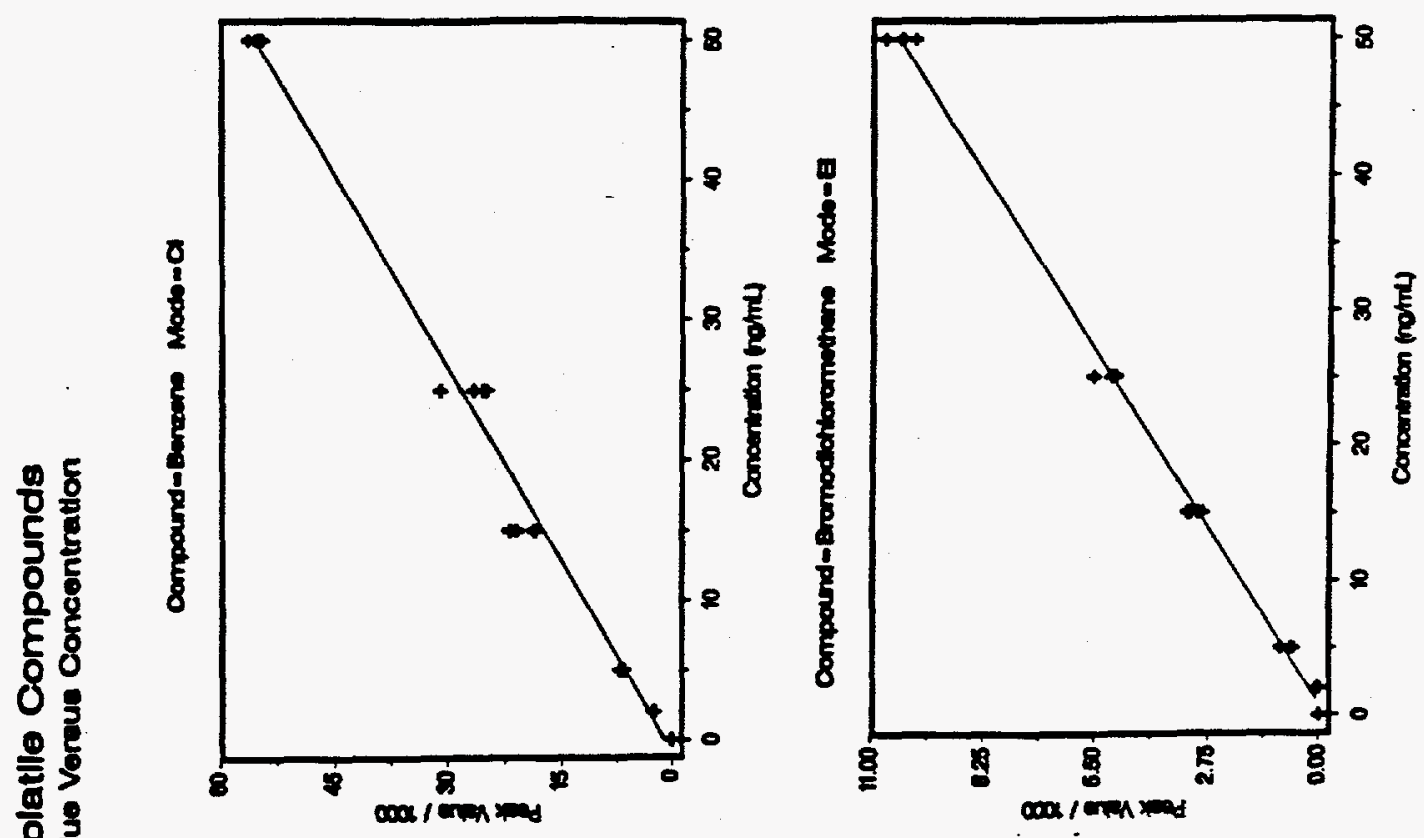

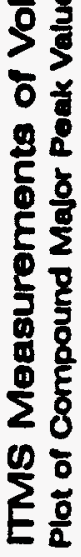
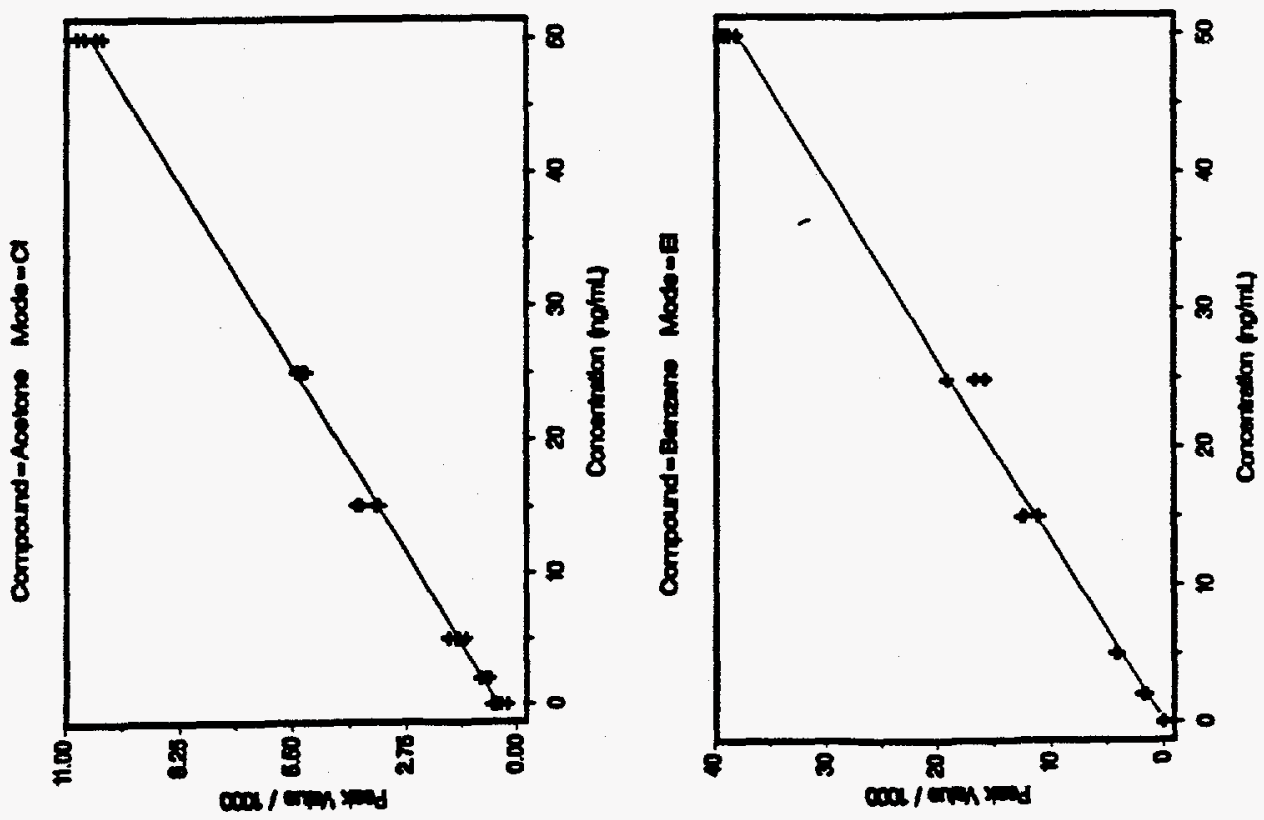

$8265-51$

Revision WG

Nov. 1996 
Table 11

VOC CALIBRATION CONCHNTRATIONS VS STOCK VOC USED

Target VoC Concentration $\mathrm{ng} / \mathrm{mI}$

0

10

50

250

500

1000
Volume of Forking stock $(\mathrm{ml})$ Required for $10 \mathrm{~L}$ Air

0

0.1

0.5

2.5

5.0

10 
Table 12

\section{LIST OF THIRTY-TWO EPA TARGET COMPOUNDS, DETECTION LIMITS IN AIR AND CHARACTERISTIC IONS}

\begin{tabular}{|c|c|c|c|c|}
\hline \multirow{2}{*}{ Compound } & \multicolumn{2}{|c|}{ Electron Impact } & \multicolumn{2}{|c|}{ Chemical lonization } \\
\hline & $\begin{array}{l}\text { Peak } \\
(\mathrm{m} / \mathrm{z})\end{array}$ & $\begin{array}{l}\mathrm{MDL} \\
(\mathrm{ppb})\end{array}$ & $\begin{array}{l}\text { Peak } \\
(\mathrm{m} / \mathrm{z})\end{array}$ & $\begin{array}{l}\mathrm{MDL} \\
\text { (ppb) }\end{array}$ \\
\hline Acetone & & & 58 & 12.1 \\
\hline Benzene & 78 & 21.2 & 79 & 41.7 \\
\hline Bromodichloromethane & $83+85$ & 2.3 & & \\
\hline Bromoform & $171+173+175$ & & & \\
\hline Bromomethane & 94 & 53.1 & & \\
\hline Carbon Disulfide & 76 & 3.1 & & \\
\hline Carbon Tetrachloride & $117+119+121$ & 5 & & \\
\hline Chlorobenzene & 112 & 16.2 & 113 & 12 \\
\hline Chloroethane & 49 & 167 & & \\
\hline Chloroform & $83+85$ & 16.5 & & \\
\hline Chloromethane & & & & \\
\hline Dibromochloromethane & $127+129+131$ & 3.6 & & \\
\hline 1,1-Dichloroethane & 62 & 8.1 & & \\
\hline 1,2-Dichloroethane & 61 & 12.4 & & \\
\hline 1,1-Dichloroethene & $96+98$ & 14.4 & & \\
\hline cis-1,2-Dichloroethylene & 96 & 10.8 & & \\
\hline trans-1,2-Dichloroethylene & 96 & 11.7 & & \\
\hline Dichloromethane & 47 & 16.6 & & \\
\hline 1,2-Dichloropropane & 76 & 10.2 & & \\
\hline cis-1,3-Dichloropropene & $75+77$ & 1.4 & & \\
\hline trans-1,3-Dichloropropene & $75+77$ & 3 & & \\
\hline Ethyl Benzene & 105 & 20.5 & 107 & 13.7 \\
\hline 2-Hexanone & 100 & 104 & 101 & 34.5 \\
\hline Methyl Ethyl Ketone & 72 & 37.4 & 73 & 46.2 \\
\hline Methyl Isobutyl Ketone & 100 & 33.2 & 101 & 15.9 \\
\hline Styrene & 104 & 12.5 & 105 & 12.2 \\
\hline 1,1,2,2-Tetrachloroethane & $83+85$ & 27.1 - & & \\
\hline Tetrachiloroethylene & $164+166+168$ & 11.8 & & \\
\hline Toluene & 91 & 3.4 & 93 & 5.7 \\
\hline
\end{tabular}


Table 12 (continued)

\begin{tabular}{|c|c|c|c|c|}
\hline \multirow{2}{*}{ Compound } & \multicolumn{2}{|c|}{ Electron Impact } & \multicolumn{2}{|c|}{ Chemical Ionization } \\
\hline & $\begin{array}{l}\text { Peak } \\
(\mathrm{m} / \mathrm{z})\end{array}$ & $\begin{array}{l}\text { MDL } \\
(\mathrm{ppb})\end{array}$ & $\begin{array}{l}\text { Peak } \\
(\mathrm{m} / \mathrm{z})\end{array}$ & $\begin{array}{l}\mathrm{MDL} \\
(\mathrm{ppb})\end{array}$ \\
\hline 1,1,1-Trichloroethane & $97+99$ & 14.7 & & \\
\hline 1,1,2-Trichloroethane & 96 & 4.5 & & \\
\hline Trichloroethylene & $130+132$ & 5.9 & & \\
\hline Vinyl Acetate & 87 & 61.1 & & \\
\hline Vinyl Chloride & & & & \\
\hline Xvlenes & 105 & 8.9 & 107 & 8.1 \\
\hline
\end{tabular}


TABLE 13

SPIKE RECOVERY DATA ON USATHAMA SOIL VS WATER BY DSITMS

SPIKE CONCENTRATION $=200 \mathrm{ppb}$

Sample ID
\begin{tabular}{|l|l|l|l|l|l|} 
Chloroform & \multicolumn{1}{c}{$\begin{array}{c}\text { Toluene } \\
\text { (Peak Area) }\end{array}$} & \multicolumn{2}{c}{$\begin{array}{c}\text { Carbon TET } \\
\text { (Peak Area) }\end{array}$} & $\begin{array}{c}\text { TCE } \\
\text { (Peak Area) }\end{array}$ & $\begin{array}{c}\text { PCE } \\
\text { (Peak Area) }\end{array}$ \\
\hline 1 (Soil EI) & $113 \%$ & & $61 \%$ & $74 \%$ & $87 \%$ \\
\hline 1 (Soil CI) & & $73 \%$ & & & \\
\hline 2 (Soil EI) & $91 \%$ & & $90 \%$ & $93 \%$ & $92 \%$ \\
\hline 2 (Soil CI) & & $67 \%$ & & & \\
\hline
\end{tabular}


APPENDIX B

\section{LABORATORY DATA DELIVERABLES}




\section{B-3}

Laboratory Data Deliverables

\begin{tabular}{ll}
\hline \multicolumn{1}{c}{ Requirements } & \multicolumn{1}{c}{ Deliverables } \\
\hline $\begin{array}{l}\text { Documentation of sample receipt } \\
\text { Discussion of laboratory analysis, } \\
\text { including any laboratory problems }\end{array}$ & $\begin{array}{l}\text { Signed chain-of-custody forms } \\
\text { Case narrative }\end{array}$ \\
Precision and accuracy & Control charts \\
Organics \\
Sample results & $\begin{array}{l}\text { Contract Laboratory Program } \\
\text { (CLP) Form 1, or equivalent, } \\
\text { including tentatively identified }\end{array}$ \\
System monitoring/surrogate recoveries & CLP Form 2, or equivalent \\
Spike recovery & CLP Form 3, or equivalent \\
Method blank data & CLP Form 4, or equivalent \\
Instrument performance check & CLP Form 5, or equivalent \\
Initial calibration data & CLP Form 6, or equivalent \\
Continuing calibration check & CLP Form 7, or equivalent \\
Internal standard check & CLP Form 8, or equivalent \\
Pesticide identification summary & CLP Form 10, or equivalent \\
\hline
\end{tabular}




\section{DISTRIBUTION}

1. L. V. Asplund

2-6. V. L. Turner

7. H. C. Newsom

8-9. P. T. Owen

10-12. L. B. Raulston

13. File-EMEF DMC-RC

14-19. C. A. Provost, CDM Federal Programs Corporation, Suite 500, 800 Oak Ridge Turnpike, Oak Ridge, TN 37830

20. B. A. Skokan, Remediation Project Engineer, U.S. Department of Energy, Cloverleaf Building, Room 2165, 19901 Germantown Road, Germantown, MD 20874

21-22. R. C. Sleeman, Director, Environmental Restoration Division, U. S. Department of Energy Oak Ridge Operations Office, P.O. Box 2001, Oak Ridge, TN 37831-8541

23. J. W. Wagoner II, Supervisory Remediation Project Engineer, U.S. Department of Energy, Cloverleaf Building, Room 2163, 19901 Germantown Road, Germantown, MD 20874 